\title{
A corpus-based two-level model of situation aspect ${ }^{1}$
}

\author{
ZHONGHUA XIAO \& ANTHONY MCENERY
}

\section{Lancaster University}

\author{
(Received 8 August 2002; revised 28 August 2003)
}

In this paper we will extend Smith's (1997) two-component aspect theory to develop a two-level model of situation aspect in which situation aspect is modelled as verb classes at the lexical level and as situation types at the sentential level. Situation types are the composite result of the rule-based interaction between verb classes and complements, arguments, peripheral adjuncts and viewpoint aspect at the nucleus, core and clause levels. With a framework consisting of a lexicon, a layered clause structure and a set of rules mapping verb classes onto situation types, the model is developed and tested using an English corpus and a Chinese corpus.

\section{INTRODUCTION}

According to Smith (I997), the aspectual meaning of a sentence is the synthetic result of SITUATION ASPECT and VIEWPOINT ASPECT. The former refers to the intrinsic aspectual properties of IDEALIZED SITUATIONS, while the latter refers to the speaker's choice of a perspective from which a situation is presented. The two are independent yet interacting components of twocomponent aspect theory. In this paper we will extend Smith's (I997) two-component aspect theory to develop a two-level model of situation aspect in which situation aspect is modelled as VERB CLASSES at the lexical level and as SITUATION TYPES at the sentential level.

At the lexical level, we use a five-way classification system, established in this paper (section 4), to classify situation aspect into six verb classes (section 5). These verb classes constitute the lexicon of our two-level model of situation aspect. At this level, verbs alone are considered. An essential concept that enables us to do this is NeUTRAL CONTEXT. For the moment, it suffices to say that a neutral context is a simple clause in which everything

[I] We are obliged to the Economic and Social Research Council (ESRC) for funding some of the work presented in this paper (Grant reference No. RES-0oo-220I28). We would also like to thank the anonymous referees of the Journal of Linguistics, as well as Jim Miller, for kindly commenting on an earlier version of this paper. An earlier, shorter version of this paper was presented at the 5th Chronos Colloquium on Tense and Aspect, held in Groningen in June 2002, and a rudimentary version of our two-level aspect model was published in Journal of Universal Language 3.2, pp. I39-177. 
that might change the aspectual value of a verb is excluded, though we will refine this definition in section 5 .

Sentential-level situation aspect is the composite result of the interaction between verb classes and complements (e.g. push the door OPEN), arguments (e.g. cooked THE TURKEY), and non-arguments such as peripheral adjuncts (e.g. read the book FOR IO MINUTES) and viewpoint aspect (e.g. Mary WAS SINGING A SONG when she died; Comrie I976: 47). According to Van Valin (forthcoming), there are three levels of syntactic units of the layered structure of the clause (LSC), namely, NUCLEUS, CORE and CLAUSE. These correspond to the three levels of semantic units: predicate, predicate plus arguments, and predicate plus arguments as well as non-arguments. The three levels of the LSC that Van Valin proposes for his Role and Reference Grammar is a useful point of departure for us to explore the composition of situation aspect at the sentential level. In our model, the sentential level composition of situation aspect takes place at the three levels of syntactic units. The interaction between verbs and other sentential constituents (i.e. complements, arguments and non-arguments) is governed by a set of rules that map verb classes at the lexical level onto situation types at the sentential level.

It should be noted, however, that while situation aspect is modelled at the lexical and sentential levels in our analysis, the same classification system applies to both verb classes and situation types. With a framework consisting of a lexicon, a layered clause structure and a set of mapping rules, our model of situation aspect was developed and tested with data from an English corpus and a corpus of Mandarin Chinese. Before we present our new model, however, it is appropriate to review previous proposals and outline our methodology, which will be done in sections 2 and 3 respectively.

\section{Previous studies of situation aspect}

While the earliest literature on aspectual classification dates as far back as Aristotle, modern approaches to aspect are normally considered to start with Vendler (I967), who proposed a four-way aspectual classification based on the verb classes STAte, ACTivity, ACComplishment and ACHievement, as well as linguistic criteria to differentiate between these verb classes. Vendler's four verb classes can be differentiated using three binary features: [ \pm DYNamic], [ \pm DURative] and [ \pm TELIC] (cf. Shirai 2002: 456), as shown in Table I.

As can be seen in the table, Vendler's analysis basically works at the lexical level (cf. Verkuyl I993: 33), though it also involves predicates rather than simply verbs alone. As such, Vendler has to put run and walk under the category of activity, and run a mile and walk to school under the category of accomplishment. With the three traditional parameters alone, a double entry for the same verb in the lexicon is inevitable, thus making the lexicon unnecessarily large. Furthermore, Vendler's verb-based approach not only 


\begin{tabular}{lcccll}
\hline Class & {$[ \pm$ dyn $]$} & {$[ \pm$ dur $]$} & {$[ \pm$ telic $]$} & Examples \\
\hline STA & - & + & - & know, love, believe, possess \\
ACT & + & + & - & run, walk, swim, push a cart \\
ACC & + & + & + & run a mile, walk to school, paint a picture \\
ACH & + & - & + & recognize, spot, find, lose, reach, win \\
\hline
\end{tabular}

Table I

Vendler's four verb classes

obscures the fact that we are talking about a single verb (cf. Lys \& Mommer 1986: 216), it is also inadequate as an account of aspectual meanings arising from arguments and non-arguments (e.g. read vs. read a book; cf. section 6). Yet Vendler's (1967) quadripartite analysis, though having weaknesses, has been very influential and has been accepted as a useful starting point in the study of aspect by many authors (e.g. Carlson I98I; Mourelatos I98I; Moens 1987; Verkuyl 1989; Smith 1997).

To date, however, the reinterpretations of Vendler have led to models which, while they may deal with some issues effectively, simply generate others. Mourelatos (I98I), for example, uses Kenny's (1963) partial ordering tree to reconstruct Vendler's verb classes. Mourelatos' main partition involves three verb classes: STATES, PROCESSES and EVENTS. Mourelatos draws an analogy between the 'count feature' (Mourelatos I98I: 204) of situations and the mass-count distinction in nouns. While states and OCCURRENCES (i.e. processes and events) can be differentiated on the basis of [ \pm dynamic], the two types of occurrences are different in that events can be counted whereas processes cannot. Mourelatos (198I: 200) proposes collapsing Vendler's accomplishments and achievements into one category: events. In his analysis, therefore, the difference between the two is at best a secondary distinction. Thus, while events are further divided into developments and punctual occurrences according to their temporal lengths, processes are not. However, as we will see later in this section and in section 4.2, [ \pm durative] is indeed an important parameter for aspectual classification. A further problem with Mourelatos' classification is that he places 'split-second events' like blink and hit together with Vendler's achievements, under the label of punctual occurrences. This conflation cannot account systematically for the distinction between the two types of punctual events (see sections 5 and 7 ). Mourelatos (I98I: 199), however, does identify, unlike many other works, the effect of sentential constituents on situation aspect, namely, the inherent features of verbs, the nature of arguments (though he incorrectly includes external arguments; see section 6.2), adverbials, viewpoint aspect and tense (see discussion of neutral context in section 5).

Vendler's attempt to classify surface verbs once and for all is clearly infeasible (cf. Dowty 1979: 62), as situation aspect is a sentence-level 
phenomenon (cf. Verkuyl 1993; Smith 1997). While Vendler was aware of the contributions of arguments to verb classes, it was Verkuyl (1993) who elaborated the compositional nature of situation aspect in a systematic way. However, Verkuyl's (1989, I993) approach to aspectual classification is also problematic. In his analysis, the feature [ \pm durative] (cf. section 4.2) is not linguistically significant. Verkuyl (I989: 56f.) argues that as modern technology has made it possible to produce a standard business letter by hitting a single key, the distinction between typing a (business) letter (accomplishment) and typing the letter $p$ (achievement) depends on something that has nothing to do with language itself.

While situations in the real world may be just as Verkuyl suggests, it should be noted that we are actually classifying the LINGUISTIC EXPRESSION of these real world situations instead of the real world situations per se (cf. Siewierska I99I : 232). The reason for this is that when we discuss aspectual classification, we are actually talking about linguistic conventions rather than real world situations (cf. Smith 1988: 225; Siewierska I99I: 232). As Bach (I98I: I5) suggests, our linguistic inquiry into ontological presuppositions should concern only those that can be found in our understanding of the world as it is reflected in linguistic categories (cf. also Shirai \& Andersen I995: 744). Link (1983: 303) also argues that 'our guide in ontological matters has to be language itself'. The pragmatic approach taken by Verkuyl implies that the difference between [ + durative] and [-durative] situations is quantitative, that is, there are short accomplishments and long achievements. But in fact the qualitative difference between the two cannot be eliminated because achievements are conceived as filling or taking up no time at all. That explains the ill-formedness of *John reached the summit for a split second. ${ }^{2}$

Furthermore, some of Verkuyl's (1989, 1993) rules mapping verbs onto situation types, e.g. the effect of external arguments, are incorrectly postulated. Verkuyl (I989: 80), for example, uses the examples in (I) to argue that subject NPs also contribute to situation aspect.

(I) (a) Soldiers played that sonata. (Verkuyl I989: 80) ${ }^{3}$

(b) Adults hated that sonata. (ibid.)

(c) Nobody hated sonatas. (ibid.)

[2] In this paper, the asterisk * is used to indicate an unacceptable utterance. It should be noted, however, that while some Chinese examples cited in this paper are ill-formed, their English equivalents are perfectly felicitous.

[3] All numbered examples in this paper are cited from our corpora, either directly or in a modified form, unless indicated otherwise. It should be noted that modified examples may NOT necessarily be grammatical or acceptable. A citation from corpora or other sources is typically modified in this paper to (i) provide an unacceptable example, or (ii) to form a more marked contrast with other examples. An in/for-PP, which does not appear in the original text, may appear in brackets in an example. It is included as a test for the telicity value of a situation. 
According to Verkuyl (I989: 8I), the sentences in (I) are [-telic] (or [-T] in his own terms) because they 'have subject-NPs with a minus value' of the feature B, i.e. bare plurals or mass nouns. When a sentence has a $[-\mathrm{B}]$ subject NP, the aspectual value of the sentence (S-aspect) is [-telic] no matter whether the verb phrase (i.e. VP-aspect, including internal arguments) is [+telic] or [-telic], thus

(2) (a) Subject-NP $-\mathrm{P}_{[-\mathrm{B}]}+\mathrm{VP}_{[+\mathrm{T}]} \Rightarrow$ Sentence $_{[-\mathrm{T}]}$ (e.g. (Ia, b)) (ibid.: 8I)

(b) Subject-NP $\mathrm{N}_{[-\mathrm{B}]}+\mathrm{VP}_{[-\mathrm{T}]} \Rightarrow$ Sentence $_{[-\mathrm{T}]}$ (e.g. (Ic)) (ibid.: 8I)

Verkuyl is right to argue that (Ib) and (Ic) are [-telic], but his explanation of why this is the case is not convincing at all. The two situations are atelic simply because hate is a [-telic] verb. Atelic verbs typically produce atelic situations, disregarding the nominal feature of internal or external arguments (see section 6.2). Example (Ia) is slightly more complicated because of the bare plural soldiers. As will be seen in section 6.2, bare plurals and mass nouns are not necessarily [ $-\mathrm{B}]$ (or [-count], as used in our model). When a speaker says Soldiers played that sonata, he/she must have in mind a particular group of soldiers, for example, a group of soldiers at a party in a club. In this context, it is quite unlikely that the bare plural refers to soldiers in general. This means that soldiers in (Ia) is [ $+\mathrm{B}]$ and, therefore, in our analysis, (Ia) should be [ + telic] because (Ia) will certainly pass the entailment test: Soldiers were playing that sonata does not entail Soldiers played that sonata. It is true that (Ia) can take a durative adverbial like for 5 minutes (see section 4.3) felicitously (i.e. Soldiers played that sonata for 5 minutes). And in this case, the revised sentence is indeed [ - telic]. But the aspectual shift is attributable to for 5 minutes because a for-adverbial can delimit a telic situation and coerce it into an atelic situation at the clause level (see section 6.3). In fact, while a for-adverbial does not usually pair with a telic situation, it is not difficult to find instances of this co-occurrence. Consider the example in (3).

(3) For a second, a slightly wounded expression crossed Neil's face [...]

The situation 'a wounded expression crossing Neil's face' in (3) is [+telic] at the core level (see section 6.2). But when the sentence takes for a second, it is coerced into a BOUNDED ACTIVITY (see sections 6.3 and 7) at the clause level. Therefore in (3), the accomplishment 'cross Neil's face' may not have achieved its final endpoint, i.e. the wounded expression was not expressed fully on Neil's face within the specified time frame. For the moment, let us leave the issue of external arguments to one side and focus instead on another influential aspect model, that of Moens (1987). We will, however, return to the issue of external arguments in section 6.2.

Moens (1987) presents an aspectual network in which a basic distinction is made between EVENTS and STATES. Using two binary criteria, i.e. atomic vs. extended, and [ + consequent] vs. [-consequent], Moens subdivides events into four categories, as shown in Table 2. 


\begin{tabular}{|c|c|c|c|}
\hline \multirow[b]{2}{*}[\pm\text{consequent}]{} & \multicolumn{2}{|c|}{ EVENTS } & \multirow[b]{2}{*}{ STATES } \\
\hline & Atomic & Extended & \\
\hline$[+$ consequent $]$ & $\begin{array}{l}\text { culmination } \\
\text { (e.g. die, win) }\end{array}$ & $\begin{array}{l}\text { culminated process } \\
\text { (e.g. erect) }\end{array}$ & $\begin{array}{l}\text { habitual state } \\
\text { consequent state }\end{array}$ \\
\hline$[-$ consequent $]$ & $\begin{array}{l}\text { point } \\
\text { (e.g. knock, blink) }\end{array}$ & $\begin{array}{l}\text { process } \\
\text { (e.g. work, run) }\end{array}$ & $\begin{array}{l}\text { progressive state } \\
\text { lexical state }\end{array}$ \\
\hline
\end{tabular}

Table 2

Moens' aspectual classification

preparatory process $\mid$ consequent state
culmination point
Figure I
Moens' event nucleus.

It is clear that three of Moens' event types, i.e. CULMination, CULMinATED PROCESS and PROCESS, correspond to Vendler's achievement, accomplishment and activity. In addition, Moens identifies a new event type POINT, which is referred to as SEMELFACTIVE in our model (cf. sections 5 and 7 ). Moens (1987: 64f.) suggests that each of his aspectual classes is associated with a part of his tripartite EVENT NUCLEUS, as shown in Figure I.

Moens' identification of point as a separate category is significant as it explains why some punctual events (i.e. points or semelfactives) can take the progressive whereas others (i.e. achievements) cannot. However, the problems with Moens' system are self-evident. Firstly, it is not clear which part of the nucleus his new category of point should be associated with. It cannot be the CULMINATION POINT because the point category carries the value of [-consequent]. Secondly, if the process category pertains to the PREPARATORY PROCESS, there must be something to be prepared for. However, processes do not have a culmination point to prepare for; similarly, not all states are consequent. Thirdly, Moens has shoehorned 'habitual', 'consequent' and 'progressive' states, etc. into the category of STATE and yet barely discusses this complicated category. These deficiencies in Moens' one-component aspect model encouraged us to follow Smith's (I997) two-component aspect theory (cf. section I).

In contrast to Vendler's verb-based approach, Smith (I997) focuses her aspectual classification directly on idealized situations at the sentential level. Table 3 is a feature matrix system of Smith's situation types with her own examples. 


\begin{tabular}{lcccl}
\hline Situation & {$[ \pm$ dyn $]$} & {$[ \pm$ dur $]$} & {$[ \pm$ telic $]$} & \multicolumn{1}{c}{ Examples } \\
\hline STA & - & + & $*$ a & know the answer, love Mary \\
ACT & + & + & - & laugh, stroll in the park \\
ACC & + & + & + & build a house, walk to school \\
SEM & + & - & - & tap, knock \\
ACH & + & - & + & win the race, reach the top \\
\hline
\end{tabular}

[a] Smith (I99I: 30, I997: 20) does not assign any telicity value to states because she thinks a final endpoint is irrelevant to this situation type. But as will become apparent in section 6.3, states may also have a final temporal endpoint when they are delimited by devices like temporal adverbials at the clause level, as in (26a).

\section{Table 3}

Smith's (1997) situation types

Smith's classification does not appear to differ much from Vendler's. The only noticeable difference is that semelfactives are separated from Vendler's activities to reflect the distinction between achievements and accomplishments. Conceptually, however, Smith's reconstruction is significant. As noted earlier, a striking feature of Vendler (1967) is that he confined his partition to the lexical level, as "what he really did is to propose ontological categories' (Verkuyl 1993: 33). In contrast, Smith (1997) is aware of the compositional nature of situation aspect; therefore her aspectual classification is not concerned with verbs. Rather it focuses directly on idealized situations at the sentential level. Smith (1997: 54f.) also suggests some rules to govern the interaction between verbs and arguments in the composition process of situation aspect. However, her rules are only concerned with NP and PP-arguments. Furthermore, as she has not established an aspectual classification of verbs at the lexical level, these rules cannot be applied easily, if at all. As Lys \& Mommer (1986: 218) argue, 'unless a system of verb classification is also set forth, many generalizations will be missed'.

As can be seen from the above discussion, none of the analyses discussed so far provides an adequate classification of situation aspect. Our two-level approach to modelling situation aspect is primarily motivated by the deficiencies inherent in these analyses. The Vendlerian approach works well at the lexical level, but not at the sentential level. Conversely the approach of Smith works well at the sentential level but not at the lexical level. Our two-level approach to situation aspect seeks to bridge this gap, operating at both the lexical and the sentential levels. Moens' failure to give an adequate account of his complicated category of state has led us to treat viewpoint aspect as an independent yet interacting component of aspect theory. Verkuyl's elaboration of the compositional nature of situation aspect has encouraged us to elaborate detailed rules mapping verb classes at the lexical level onto situation types at the sentential level. 


\section{OUR METhOdOLOGY AND CORPORA}

While 'linguistic analysis will benefit if it is based on real language used in real contexts' (Meyer 2002: II), previous studies of aspect have largely been conducted without recourse to attested language data. They have, rather, been based on a handful of confected examples which, if not intuitively unacceptable, are atypical of attested language use (cf. Xiao 2002: 4). Furthermore, those proposals have not, to date, been tested with corpus data. Yet corpora have a role to play both in developing and testing such theories, as demonstrated in the remaining sections of this paper.

With that said, we do not mean that the corpus-based approach and the intuition-based approach are completely exclusive, rather the two are complementary (cf. McEnery \& Wilson 200I: I9). With the intuition-based approach, researchers can invent purer examples instantly for analysis because intuitions are readily available and invented examples are free from language-external influences existing in naturally occurring language. However, intuition should be applied with caution (cf. Seuren 1998: 260-262; Hunston 2002: 20-22, 43). Firstly, it is possible to be influenced by one's dialect or sociolect. As such, what appears unacceptable to one speaker may be perfectly felicitous to another (cf. Xiao 2002: 17). Secondly, when a researcher invents an example to support or disprove an argument, he/she is consciously monitoring his/her language production. Therefore, even if his/her intuition is correct, the utterance may not represent typical language use. Finally, results based on introspection alone are difficult to verify as introspection is not observable. In contrast, all of these disadvantages are circumvented by the corpus-based approach. Additional advantages of the corpus-based approach are that a corpus can reveal differences that intuition alone cannot perceive (cf. Francis, Hunston \& Manning I996; Chief, Hung, Chen, Tsai \& Chang 2000; Hunston 2002: I2f.) and a corpus can yield reliable quantitative data. Hence we decided to undertake a corpus-based approach to modelling situation aspect.

The use of corpus data as an input to the semantic analysis of aspect, a methodology to be elaborated in the following sections, represents something new. Our study seeks to achieve a marriage between theory-driven and corpus-based approaches to linguistics, with the goal of providing an effective and fruitful avenue for the study of aspect. We believe that the discussion of external arguments in section 2 demonstrates quite clearly some of the value of corpus data in correcting biased intuitions.

The Chinese corpus used in this paper, the Weekly Corpus, was built with texts current in China in 1995, totalling 138,694 Chinese characters (cf. Xiao 2002: 24). While the corpus itself is small, one need not necessarily apologize for using a small corpus in the right circumstances, as the size of the corpus needed to explore a research question is dependent on the frequency and distribution of the linguistic features under consideration in that corpus 
(cf. McEnery \& Wilson 200I: 80); small corpora may contain sufficient examples of frequent linguistic features. As aspect is a frequent feature of the Chinese language, the Chinese corpus used in our study yielded more than enough examples for our purpose. The English corpus used in this paper, FLOB, a one-million-word balanced corpus of present-day British English (the Freiburg-LOB Corpus of British English; cf. Hundt, Sand \& Siemund 1998), also yielded enough examples of aspect marking for our purpose. Our aim in using the corpora was to establish the components of our model (sections 5 and 7) and provide a basis for the quantification of our aspectual classification system (section 4) and rules governing the composition of situation aspect (section 6).

\section{The Classification SyStem For Situation ASPECT}

The first step in modelling situation aspect is to establish a classification system (cf. Vendler 1967; Verkuyl 1993; Smith 1997). The selection of parameters, however, needs to be undertaken with regard to a defensible rationale. This paper claims that the relevant distinguishing features should not only make a clear distinction between various types of verbs and situations, they must also facilitate the explanation of the interaction between situation aspect and viewpoint aspect. In doing so, this paper will build upon the three established parameters, [ \pm DYNamic], [ \pm DuRative] and [ \pm TELIC] (e.g. Comrie 1976; Smith 1997), and add two new features, [ \pm Result] and [ \pm BOUNDED], to complete our classification system.

\section{I $[ \pm$ Dynamic]}

The feature [ \pm dynamic] is generally given priority over other parameters to serve as the central criterion for the initial level distinction of situation aspect (e.g. Brinton I988: 57; Smith 1997: 19). A [-dynamic] situation has no internal phases and involves no change (e.g. know). In contrast, a [+dynamic] situation necessarily involves change through time, which can be related either to its heterogeneous internal structure (e.g. dance) or to its changing endpoints (e.g. die). One of the syntactic tests that have been extensively adopted to determine dynamicity is the progressive test proposed by Vendler (1967). While the reliability of the progressive test in English is sometimes questioned (e.g. Leech 197I: I-27; Comrie 1976: 37f.; Dowty 1979: I84), the intuition underlying Vendler's observation is, in our view, correct, though Vendler's observation should be expressed as 'stative verbs do not need a progressive auxiliary in contexts where other verbs do' (Moens I987: 136). The progressive test appears reliable in Chinese, where the progressive aspect marker is zai. Of the 88 instances where the progressive $z a i$ appears in the Weekly Corpus, 86 denote dynamic situations and two are special cases of stative situations (see section 5.3), which are 'more event-like' and 'more 
akin to things that HAPPEN' (Carlson 1977: 448). For example, the verb xizao 'to take a bath' can take the progressive zai and is judged as a dynamic verb. However, because yongyou 'to own' is a stative verb, it cannot take the progressive zai.

\section{2 [ \pm Durative]}

[ \pm Durative] as a feature relies on the contrast between a [ + durative] situation, which 'lasts for a certain period of time', and a [-durative] situation, which 'does not last in time' (Comrie 1976: 4If.). Durativity is a mental concept, hence duration is relative and can be of any specified temporal length. For example, John slept is durative whereas John coughed is punctual. What matters of course is not how much time John's sleep or cough actually takes but that a typical cough is so short that conventionally speakers do not focus on its internal structure (see section 2). With a punctual reference time, durative situations either have an inceptive reading (e.g. The phone rang at Io a.m.) or are unacceptable (e.g. *John was tall at Io a.m.). In Chinese, the most reliable test for durativity is the collocation test with the durative aspect marker -zhe. For example, of the 238 instances of the durative $-z h e$ found in the Weekly Corpus, 236 are activities (e.g. xiao 'smile') while the other two involve semelfactives (e.g. pai 'pat'), which actually behave like activities when denoting multiple events (cf. section 5.I).

\section{$4 \cdot 3$ [土Telic]}

While the consensus is that the [ \pm telic] distinction is essential to aspectual classification, there is no uniform definition of telicity. For Garey (I957: 106), an action is telic if it tends 'towards a goal'. Comrie $(1976: 45,47)$ defines a telic situation as 'one that involves a process that leads up to a well-defined terminal point'. Smith (1997: 19) simply associates the [ \pm telic] distinction with the nature of the final endpoint: while telic events have a natural final endpoint, atelic events have an arbitrary final endpoint. Note that telicity is defined here differently from previous proposals. In our model, the feature $[ \pm$ telic $]$ is associated with the presence or absence of a FINAL SPATIAL ENDPOINT (see section 4.5 for the distinction between a final spatial endpoint and a FINAL TEMPORAL ENDPOINT).

Several behavioural tests have been suggested in the literature to determine the telicity of a situation. The entailment test proposed by Garey (1957: 195) is widely accepted (e.g. Vendler 1967; Comrie 1976: 44f.). Garey (ibid.) asserts that the telicity value of a verb can be tested with the question 'if one is verbing but interrupted while verbing, has one verbed?' With an atelic situation, like swimming or singing, the answer is 'yes', while with a telic situation like drowning or making a chair, the answer is 'no'. The entailment test, however, does not apply to Chinese because the negative adverb mei 
'not' negates the REALIZATION rather than the COMPLETION of an event. For example, ta mei kan na-ben shu 'He didn't read that book' means that the reading event did not occur at all. To express the meaning intended in the entailment test, the RVC (resultative verb complement) form kan-wan 'to read-finish' must be used: ta mei kan-wan ne-ben shu 'He didn't finish reading that book'.

Ever since Vendler (I967: IOI), the compatibility test with for/in-adverbials has been in operation as a diagnostic for determining the telicity value of a situation. A [-telic] situation is compatible with a for-adverbial (e.g. John walked FOR AN HOUR) whereas a [+telic] situation is compatible with an in-adverbial (e.g. John wrote a letter IN AN HOUR). The Chinese equivalents of in an hour and for an hour, (zai) yi-ge xiaoshi nei and yi-ge xiaoshi respectively, also work well (e.g. zai qi-fenzhong nei daoda 'to arrive in seven minutes' and shouhou yi-tian 'to wait for one day'). All of the thirteen instances of in-PPs found in the Weekly Corpus indicate the $[+$ telic] value of the situations concerned.

As noted in section 2, it is important to classify verbs and situations at two different levels. But if one uses only the three traditional parameters, the problem of the double lexicon entry encountered by Vendler cannot be avoided. To avoid this problem it is necessary to introduce two new binary features, namely, $[ \pm$ result $]$ and $[ \pm$ bounded $]$.

\section{4 [ \pm Result]}

In our model, a verb is assigned the value of [+ result] if its meaning includes a reference to a changing point at which the final spatial endpoint denoted by the verb starts holding (cf. Moens 1987: I40). Telic verbs do not necessarily encode a result. While an achievement verb and an accomplishment verb both have a final spatial endpoint, they differ in that the former indicates the success of achieving that endpoint (e.g. ying(qiu) 'to score (a goal)') but the latter does not (e.g. xie(xin) 'to write (a letter)'). The examples in (4) and (5) below illustrate this point well. The verb ate in (4a) involves a potential final spatial endpoint, which is made explicit by the internal argument nine ham rolls. However, as the verb does not encode a result itself, once the internal argument is optionally absent, as in (4b), an accomplishment verb no longer has a final spatial endpoint and can only allow an atelic reading. [+ Result] verbs are different. They always have a telic reading whether or not there is an additional argument indicating a final spatial endpoint, as shown in (5).

(4) (a) She $[\ldots]$ ate nine ham rolls (in/*for Io minutes).

(b) Bullseye [...] ate like a horse (*in/for an hour).

(5) (a) He won the World Match-play title (in/*for a minute).

(b) Dan won (in/*for a minute). 
As [+ result] verbs include a reference to the successful achievement of the encoded final spatial endpoint, situations denoted by these verbs cannot be contradicted by a conjoined second clause. For example, if you assert that tamen quxiao-le na-chang bisai 'They cancelled the game' in the first clause, you cannot possibly contradict this assertion by saying *keshi mei quxiaocheng '*but did not succeed' in a conjoined clause. As such, the contradiction test can be used to determine the $[ \pm$ result $]$ value.

In this paper, we define the feature $[ \pm$ result] in line with Moens (1987: I40). It should be noted that while Smith (I997: 27, 3I) also associates some types of result with accomplishments and achievements, her interpretation of result is different from the $[ \pm$ result $]$ distinction in our model. For Smith, all [+telic] situations have a natural final endpoint that necessarily leads to a result, that is, RESULt is identified with TELICITY. In our analysis, a verb or situation is [+result] only if it encodes a result itself. Only achievement verbs carry the value of [+ result]. Our definition of result also differs from that of Shirai (199I) and Shirai \& Andersen (I995: 756), where [+result] refers to 'observable outcomes salient to the child'. In our analysis, a result associated with an achievement verb may not necessarily be observable. Rather it can be abstract as long as it is encoded in the verb itself.

\section{5 [ \pm Bounded]}

Smith (1997) classifies instantaneous events like tap and knock as semelfactives and assigns the value of [-telic] to this category (cf. section 2). As noted in section 4.3, Smith intends a [+ telic] situation to have a natural final endpoint. It is obvious that Smith does not think instantaneous situations like semelfactives have a natural final endpoint. However, this is arguable, as if semelfactives have no natural final endpoint, how can they produce iterative readings? A punctual situation, be it an achievement or a semelfactive, is conceived of as having no inherent duration, 'not even duration of a very short period' (Comrie 1976: 42), hence its initial endpoint overlaps with its final endpoint (cf. Siewierska I99I : 5I). Because of its punctual nature, we argue that the final endpoint of a punctual situation is as natural, inherent and well-defined as its initial endpoint (the two are actually the same point; cf. Jespersen 1924: 272-274; Bauer 1970: 192), though it should be kept in mind for the moment that the final endpoint of a semelfactive is different from that of an accomplishment or an achievement.

The controversy regarding the telicity value of semelfactives arises from different understandings of FINAL ENDPOINT. Traditionally, endpoints have been understood as temporal notions (e.g. Bennet \& Partee 1978). Initial and final endpoints are two points on the time axis which indicate the beginning and the ending of a situation, respectively. Later, some linguists, such as Van Voorst (I988: 27), began to interpret endpoints in terms of space. According to Van Voorst, a situation is telic only when it has an OBJECT OF 
TERMINATION, i.e. an object that undergoes an identifiable change of state. John wrote a letter is telic because a letter serves as the object of termination, whereas John walked is atelic because there is only an OBJECT OF ORIGIN (i.e. John) but no object of termination. At this point, one might be tempted to jump to the conclusion that only structures with transitive verbs can be telic, but this temptation is dangerous. In fact, not all transitive structures are telic and not all intransitive structures are atelic. For example, John wrote letters is atelic because mass nouns and bare plurals are not delimited in space and cannot serve as the object of termination. ${ }^{4}$ However, The window broke is telic because it involves a termination object that underwent an identifiable change of state. Tenny (I994: 26) also argues explicitly that telicity and boundedness are 'the same thing in two different domains: the spatial and the temporal'. They are the same thing in that they both involve final endpoints; and they are different in that they apply to different domains.

A final temporal endpoint is basically different from a final spatial endpoint. As Lyons (1977: 718) observes, 'spatial expressions are more basic, grammatically and semantically, than various kinds of non-spatial expressions'. Therefore, spatial delimitedness always implies temporal boundedness, but the reverse is not true. For example, as the situation walk to school is delimited spatially (i.e. a specified distance), it must also be bounded temporally (e.g. it usually takes John ten minutes to cover the distance). However, if John walked for only three minutes today, the situation becomes bounded temporally. In this case, the temporally bounded situation does not have a final spatial endpoint.

In our model, the feature [ \pm bounded] refers to the presence or absence of a FINAL TEMPORAL ENDPOINT while the feature $[ \pm$ telic] is related to a final spatial endpoint. It should be noted that just as [+result] always implies [+ telic], [+ telic] also implies [+ bounded]. In other words, [- result] may mean either [+telic] or [-telic]; and similarly, [-telic] may mean either [+bounded] or [-bounded]. The three endpoint-related features are hierarchically structured, with $[ \pm$ result $]$ at the top and $\left[ \pm\right.$ bounded] at the bottom. ${ }^{5}$

[4] [-Count] NPs like mass nouns and bare plurals share the property of cumulative or divisive reference (cf. Link 1983, Bach 1986). For example, milk plus milk is still milk, part of running is still running. In contrast, [+ count] NPs do not have such properties, e.g. a letter plus a letter means two letters, and part of running a mile is no longer running a mile.

[5] A $J L$ referee pointed out to us that the Jakobsonian/Prague School concept of markedness may apply here. According to the formal definition of markedness provided by Jakobson (I97I), '[t]he general meaning of a marked category states the presence of a certain (whether positive or negative) property $\mathrm{A}$; the general meaning of the corresponding unmarked category states nothing about the presence of A, and is used chiefly, but not exclusively, to indicate the absence of A' (cited from Kučera I982: I68). While markedness in a narrowed sense (i.e., 'statement of A' vs. 'statement of non-A') is operative, we maintain that markedness in a general sense (i.e., 'statement of A' vs. 'no statement of A') does not apply to the three endpoint-related parameters because [ - result $]$ in our model only means the absence of a result. While it allows both the values [ + telic] and [-telic], telicity is at a lower level. 


\section{The LEXICAL LEVEL: VERB CLASSES REDEFINED}

In this paper, verbs are classified in NEUTRAL CONTEXT, a concept similar to Moens' (1987: I3I) 'basic proposition' or Lys \& Mommer's (I986: 2I8) 'frame'. The context is deemed neutral when everything has been excluded that might change the aspectual value of a verb. This means that of the six determinants of situation aspect identified by Mourelatos (I98I: 199), the inherent features of verbs alone are taken into account. In English, for example, a neutral context is typically a simple clause in which

(a) the verb is in the past tense;

(b) the object is syntactically and semantically a singular countable noun and should only be present if it is obligatory, i.e. with a necessarily transitive verb;

(c) viewpoint aspect must be simple (cf. Lys \& Mommer 1986: 218).

Thus, John walked is neutral whereas John walked me home is not, nor is John was walking. In Chinese, a neutral context is similar except that there is no tense requirement and a perfective viewpoint aspect is preferable (e.g. ta daying-le 'He agreed'). These restrictions are imposed to avoid the possible influences of other sentential constituents (e.g. complements, arguments and non-arguments) on verbs (see section 6). Note, however, that a neutral context in our model is different from Moens' or Lys \& Mommer's concept as our notion of neutrality has no requirements for the external arguments of verbs.

There are 32 combinations of the five binary features discussed in section 4 . However, this does not mean that there are 32 verb classes because combinations of conflicting features must be ruled out. As noted in section 4.5, the three endpoint-related binary features are hierarchically structured. Therefore, feature combinations containing both [ + result $]$ and [ - telic], or both [ + telic] and [-bounded], or [ + result $]$ and [-bounded], are not possible. As the achievement of an encoded result is always punctual, feature combinations containing both $[+$ result $]$ and $[+$ durative $]$ are not possible. If a situation is instantaneous or has a final spatial endpoint, it is obvious that the situation is [+dynamic] (cf. also Lindvall I997); thus the combinations with both [-dynamic] and [-durative], or with both [-dynamic] and $[+$ telic], can also be excluded.

There are 23 combinations that group together conflicting features. Of the nine remaining combinations, three patterns are unattested in our data as basic verb classes in neutral contexts, though two of them are good as derived situation types at the clause level (cf. section 7). ${ }^{6}$ It is also interesting to note

[6] A third pattern, namely, the combination of [+dynamic], [-durative], [+bounded], $[+$ telic] and [ - result], is unattested even at the clause level. As a delimiting mechanism (e.g. from 2 to 3 p.m.) only provides a final temporal endpoint rather than a final spatial endpoint, it can only change the boundedness value but not the telicity value of a situation. 


\begin{tabular}{lccccc}
\hline Classes & {$[ \pm$ dyn $]$} & {$[ \pm$ dur $]$} & {$[ \pm$ bnd $]$} & {$[ \pm$ telic $]$} & {$[ \pm$ result $]$} \\
\hline ACTs & + & + & - & - & - \\
SEMs & + & - & \pm & - & - \\
ACCs & + & + & + & + & - \\
ACHs & + & - & + & + & + \\
ILSs & - & + & - & - & - \\
SLSs & \pm & + & - & - & - \\
\hline
\end{tabular}

Table 4

Feature matrix system of verb classes

that while on the one hand, the feature combination of [+dynamic], [+ durative], [- bounded], [-telic] and [-result] can be instantiated either as activities or as STAGE-LEVEL STATES (SLSs), on the other hand, the feature combination of [-dynamic], [+durative], [-bounded], [-telic] and [-result] can be instantiated either as INDIVIDUAL-LEVEL STATES (ILSs) or as SLSs; it is no coincidence that SLSs have sometimes been considered as a transitional class between states and activities (e.g. Carlson I98I : 39).

The six verb classes attested on the basis of our data are activities vs. semelfactives, accomplishments vs. achievements, and individual-level states (ILSs) vs. stage-level states (SLSs). The semantic features of these verb classes are summarized in Table 4.

\section{I Activity verbs vs. semelfactive verbs}

Our class of activity verbs does not differ much from Smith's (1997). They are dynamic and durative in nature, involve no final spatial or temporal endpoint and encode no result (e.g. deng 'wait', paobu 'run' and xunzhao 'look for'). The [-bounded] feature determines that their co-occurrence with durative adverbials (e.g. wo zai budui gan-le HAOJI-NIAN 'I worked in the army for many years') or the progressive (ta yizhi zAI ku 'He was crying all of the time') can only produce a durative single-event reading.

Although semelfactive verbs group with activities in that they are also dynamic verbs involving no final spatial endpoint and encoding no result, the two categories are different. Since semelfactives are prone to shift between single-event and multiple-event readings (cf. Comrie 1976: 42), their final temporal endpoints can be overridden and thus they have the feature [ \pm bounded]. In contrast with activity verbs, semelfactive verbs intrinsically involve a final temporal endpoint. Therefore, semelfactives easily suggest iterative multiple-event readings (e.g. John coughed). When a semelfactive verb takes an adverbial denoting temporal length (e.g. da-le ni JI-TIAN? 'For how many days did they beat you?'), a temporal quantifier (e.g. ye chao ta 
toushang kan-le SHU-DAO '(Liu) also chopped at her head several times with his knife'), or the progressive (e.g. ZAI guzhang 'be clapping one hands') or durative marker (e.g. YAO-ZHE tou tanxi '(she) sighed while shaking her head'), it always produces an iterative reading. Yet even in these cases, semelfactives are different from activities: the former have iterative multievent readings whereas the latter only allow durative single-event readings. So semelfactives can indeed be counted and Mourelatos' processes should be fine-grained (see section 2).

\subsection{Accomplishment verbs vs. achievement verbs}

Traditionally, these two verb classes have been distinguished primarily by the $[ \pm$ durative] feature (e.g. Smith 1997). But in our model, the difference between the two categories consists mainly of whether they do or do not encode a result (cf. section 4.4). By the [ \pm result] criterion, accomplishment verbs place emphasis on the process leading up to a result (i.e. the preparatory process in Moens' event nucleus). As the preparatory process normally takes time, accomplishments are [+durative] in nature. On the other hand, the achievement of the result encoded in an achievement verb is normally punctual, thus achievement verbs are intrinsically [-durative]. Accomplishments are verbs with the features $[+$ dynamic], $[+$ durative $],[+$ bounded], [+ telic], and [ - result] in that they focus on the process leading up to but not necessarily achieving the implied result (e.g. chi 'eat' and xie 'write'), while achievements are verbs with the features [+dynamic], [-durative], $[+$ bounded], $[+$ telic $]$, and $[+$ result $]$ in that they focus on the successful achievement of the encoded result with or without profiling the process leading up to the result (e.g. ying 'win', daoda 'arrive' and zhaodao 'find'; cf. also Yang 1995: 44).

\subsection{ILS verbs vs. SLS verbs}

One problem noted in section 4.I is that sometimes states (or more precisely, some states) can take the progressive felicitously. Any theory of aspect should be able to account for this. In this section, we will present our account of how this occurs. An important part of our account rests upon distinguishing two types of states: individual-level and stage-level states.

The distinction between individual-level and stage-level predicates was first introduced by Carlson (1977: 448). Carlson argues that stage-level predicates express transient or episodic stages of an individual (such as drunk and available). Thus they vary over time and/or place. In contrast, individuallevel predicates are predicating inherent and permanent dispositions of an individual (e.g. tall and clever); thus they remain unchanged irrespective of time and/or place. Our hypothesis that two types of states exist is also 
supported by the different ways they interact with viewpoint aspect. That is, SLSs have to be marked aspectually to have a specific closed reading, whereas ILSs do not have such a requirement (cf. Xiao \& McEnery forthcoming). ILS and SLS verbs can be defined respectively as follows: ILS verbs are stative durative verbs that do not have a final temporal or spatial endpoint and do not encode a result in the sense that they are normally predicated of permanent dispositions of an individual (e.g. xiang 'resemble' and piaoliang 'beautiful'). SLS verbs are durative and generally stative (Carlson 1977: 448; Olsen 1994) verbs that do not have a final temporal or spatial endpoint and do not encode a result in the sense that they are normally predicated of less permanent stages of an individual (e.g. bing 'be ill' and mang 'be busy').

The dichotomous treatment of states we propose in this paper is not only well justified (cf. also Carlson I98I: 39; Chierchia I995: I76-223), it is more explanatory of the behaviours of states. With the ILS/SLS distinction, the event-like properties of some states can be accounted for easily. As has been recognized in the literature, state verbs are not normally compatible with the progressive (cf. section 4.I) because they tend to describe the more permanent, or 'timeless' (Carlson 1977: 446), characteristics of an individual; but when they do occur in these contexts, they 'name the characteristics closely associated with various kinds of behaviours' (Brinton 1988: 40). In other words, they describe sTAGES of an individual, which are considered as temporary or contingent in nature (cf. Leech I971: 16; Comrie 1976: 36; Lyons 1977: 717; Smith 1983: 483f.). Compare (6a) and (6b). The verb constellation in (6a) is predicated of the individual Max himself, and the state described is related to his inherent dispositions, without which the individual would not be Max. On the other hand, the verb constellation in (6b) is predicated of stages of the individual Max, that is, his current actions or behaviours, thus (6b) can be interpreted as 'Max made a fool of himself' on a particular occasion (cf. also Carlson I98I: 36). The quality predicated by stage-level predicates can be removed without changing the essential quality of the individual. As stages of an individual are more temporary than the individual's dispositions, (6b) takes the progressive to refer to a particular stage of the individual Max.

(6) (a) Max is a fool.

(b) Max is being a fool. (Carlson 1977: 448)

The six verb classes attested on the basis of our data and redefined in this section constitute the lexicon of our aspect model. While this section has focused on the establishment of a feature matrix of verb classes, this gives an account of situation aspect at the lexical level. However, as this paper has a two-level focus, it is necessary to focus on the interaction between the lexical and the sentential levels. 


\section{ThE RULES FOR THE THREE-LEVEL INTERACTION AT THE} SENTENTIAL LEVEL

In this section, we will propose twelve rules for the composition of situation aspect at the sentential level. ${ }^{7}$ As noted in section I, the sentential level consists of three syntactic units: nucleus, core and clause. The nucleus deals with predicates. The core deals with predicates and arguments. The clause deals with predicates, arguments and non-arguments. Section 6.I is concerned with the interaction at the nucleus level (Rules I-2) and will examine the roles of RVCs (resultative verb complements) and verb reduplication in Chinese as well. Section 6.2 will discuss the effects of NP- and PP-arguments on situation types at the core level (Rules 3-6). In our model, NP-arguments have the nominal feature $[+$ count $]$ or $[-$ count $],{ }^{8}$ and PP-arguments are either $\mathrm{PP}_{\mathrm{s}_{[\text {[ocative }}} \mathrm{PP}_{\mathrm{s}_{[\text {Directional] }}}$ or $\mathrm{PP}_{[\text {Goal] }}$. Section 6.3 will discuss non-arguments that contribute to situation aspect at the clause level (Rules 7-I2), including durative adverbials specifying time frames (for-PPs, from ...to), temporal quantifiers (e.g. twice, five times), the progressive, as well as the Chinese de resultative structure and ba/bei constructions.

\section{I Nucleus level composition}

The following rules are hypothesized by us to apply to the interaction at the nucleus level:

Rule I: Verb $[-$ telic/ \pm bounded $]+\mathrm{RVCs} \Rightarrow$ Derived predicate $[+$ result $/+$ telic $]$

Rule 2: Verb $[-$ telic/ \pm bounded] + reduplicant $\Rightarrow$ Derived predicate $[+$ bounded]

Rule I illustrates the effect of RVCs on situation aspect. As Brinton (I988: I68) observes, these complements 'typically express a telic notion' and 'may add the concept of a goal or an endpoint to durative situations which otherwise have no necessary terminus' (e.g. hit the metal vs. hit the metal FLAT). RVCs refer to verb complements that indicate the resultant state or phase of the situation denoted by their preceding verbs in resultative compounds. There are three types of RVCs, namely, completive (RVCCs, e.g. xie-wan 'write-complete', zhunbei-hao 'prepare-complete'), result-state (RVCSs, e.g. sha-si 'kill-dead') and directional (RVCDs, e.g. xing-goulai 'wake up'). When these complements are added to [-telic] or even [-bounded] verbs,

[7] An anonymous $J L$ referee suggested that instead of binary features such as [ \pm telic] and [ \pm bounded], we might rather use the verb classes, established in section 5 , in our mapping rules. This, however, would make the formulations quite clumsy. For example, we would need to use 'ILS, SLS, activity and semelfactive' to replace 'verb ${ }_{\text {[telic] }}$ '

[8] The nominal feature [ \pm count $]$ is related to NP-arguments. [+Count] NPs are singular or specific countable plurals, while [-count] NPs include mass nouns and bare plurals. [ \pm Count] as used here is similar to Smith's (I997) count/mass opposition or Verkuyl's (1993) [ \pm SQA]. 
the derived predicates become [ + telic] and $[+$ result $]$ because the final spatial endpoint or result indicated by complements is attached to them. Compare ta he-le jiu 'He drank' and ta he-zuI-le jiu 'He got drunk'; while it is possible to say ta he-le jiu, keshi mei he-zUI 'He drank, but was not drunk', the version with the RVC zui (i.e. ta he-zuI-le jiu, *keshi mei he-zui '*He got drunk, but was not drunk') is not acceptable. In the Weekly Corpus, I,74I instances of RVCs were found -45 RVCCs, 864 RVCSs and 832 RVCDs. For testing, the in-PP test and the contradiction test were used (cf. sections 4.3 and 4.4). Examination of the data shows that no matter what telicity and boundedness values basic level verbs have, their derived predicates are all $[+$ telic] and $[+$ result $]$, i.e. they are achievement verbs.

In English there are no completive RVCs, and result-states RVCs can be either adjectives (e.g. pushed the door OPEN) or resultative particles (e.g. pull the cart OVER). We used situations with adjectival result-state RVCs to test the reliability of Rule I in English. Eleven situations of this type were found in FLOB, ${ }^{9}$ and Rule I passed the $i n$-PP test and the contradiction test with all of them. Consider the following examples:

(7) (a) Marie pulled her hand free (in/*for 5 minutes).

(b) Marie pulled her hand (for $/ *$ in 5 minutes).

(c) Marie pulled her hand free, *but she did not succeed.

(8) (a) He snorted his nostrils clear (in/*for I minute).

(b) He snorted his nostrils (for/*in I minute).

(c) He snorted his nostrils clear, *but his nostrils were still not clear.

The verb pull in (7) is [ - telic] and [ - bounded] (i.e. an activity) while snort in (8) is [-telic] and [ \pm bounded] (i.e. a semelfactive). But when the RVCs free and clear are added, both of them are turned into derived predicates that are $[+$ telic] and [+result] in nature. That is, RVCs function to change activity or semelfactive verbs into achievement verbs. That is why (7a) and (8a) would be infelicitous if for-adverbials were used. Similarly, as the derived predicates encode a result, they cannot be contradicted by a conjoined clause, as shown in $(7 \mathrm{c})$ and $(8 \mathrm{c})$.

Let us now consider verb reduplication in Chinese. Because of intrinsic semantic constraints, only verbs with the features [ + dynamic] and [ - result] can be reduplicated to denote a delimitative meaning in Chinese (cf. Xiao \& McEnery forthcoming). As such, wang-wang 'look-look, take a brief look' and mo-mo 'touch-touch, touch a bit' are natural whereas *pang-pang '*fat-fat' and *ying-ying '*win-win' are not acceptable. Verb reduplication not only provides a perspective from which to view a situation perfectively, it also provides a temporal boundary to the situation denoted by a

[9] Situations like 'thought the accusation unfair' and 'made her life insufferable' are irrelevant and are thus not counted. 
reduplicated verb and changes its boundedness value from minus to plus. For a final temporal endpoint, the in/for-adverbial test for a final spatial endpoint is not relevant (cf. Yang 1995). Rather, the co-occurrence test with the perfective -le will be used, as -le demonstrates a strong preference for [+ bounded] situations (cf. Xiao 2002: I5I). There are 38 instances of verb reduplication in the Weekly Corpus (36 activities and two semelfactives). Only nine are perfective situations that can take -le, but the verbs in all of these sentences must be reduplicated, even though the aspect marker -le can be optionally suppressed. Consider the following examples: ${ }^{10}$

(9) (a) wo huitou wang-le wang zhe-ge popolanlan de jia (ACT) I turn-head look-LE look this-CL run-down GEN home 'I turned around and took a brief look at this run-down home.'

(b) *wo huitou wang-le zhe-ge popolanlan de jia

(Io) (a) hanzi shayoujieshi mo[-le]-mo koudai you shuo [...] (ACT) man same-as feel[-LE]-feel pocket again say

'The man pretended to be serious about feeling in his pocket, and then said [...].'

(II) (a) laoren xiao-zhe dou-le dou shou (SEM)

old-man smile-zhe shake-LE shake hand

'Smiling, the old man shook his hand'

(b) *laoren xiao-zhe dou-le shou

Clearly, all of the (a) sentences with reduplicated verbs are felicitous whereas the (b) sentences are unacceptable. The situations of 'wang' (meaning 'to look at') in (9) and 'mo' (meaning 'to feel') in (Io) are activities, which are neither $[+$ telic] nor [ + bounded]. Therefore they cannot occur with $-l e$, as shown in (9b) and (Iob). However, when the verbs are reduplicated, the derived predicates denote temporally bounded situations, and thus can occur with -le. The verb dou 'to shake' in (II) is a semelfactive. Because verbs of this class shift easily between single-event and multiple-event readings, their temporal endpoints are often overridden. Therefore, these verbs normally group with activity verbs and usually need an extra delimiting device to provide a temporal boundary when they co-occur with -le. That explains why (IIa) is felicitous whereas (IIb) is ill-formed. Further, it is interesting to note that in (Io) -le is left out but the verb reduplicant is not and cannot be omitted. This sentence conveys a complex event situation. The first event 'mo koudai' (meaning 'to feel in his pocket') must be realized before the second event 'shuo' (meaning 'to say') can be initiated. When -le is omitted in the original sentence, the first verb constellation HAS To be reduplicated to perfectivize the first event.

[IO] In the glosses following Chinese examples, CL represents 'classifier' and GEN and PRT stand for 'genitive' and 'particle indicating mood', respectively. 


\subsection{Core level composition}

While internal arguments such as direct objects and directional complements typically affect situation type, the question of whether or not external arguments also contribute to situation aspect is controversial. Dowty (I979), Brinton (I988), Verkuyl (I989, I993) and Salaberry \& Shirai (2002: 2), for example, claim that external arguments have the same effect on situation type as internal arguments while Tenny (I994) and others argue that they do not. In our model, the rules governing the interaction between verbs and NParguments are expressed as follows:

$$
\begin{aligned}
& \text { Rule } 3: \mathrm{NP}+\operatorname{Verb}_{\left[+/- \text {telic } \Rightarrow \text { Core }_{[+/- \text {telic }]}\right.} \\
& \text { Rule } 4: \mathrm{NP}+\operatorname{Verb}_{[- \text {telic }]}+\mathrm{NP} \Rightarrow \text { Core }_{[- \text {telic }]} \\
& \text { Rule } 5: \mathrm{NP}+\operatorname{Verb}_{[+ \text {telic }]}+\mathrm{NP}_{[+/- \text {count }} \Rightarrow \text { Core }_{\left[+/- \text {telic }^{11}\right.}
\end{aligned}
$$

These rules reflect the contribution of NP-arguments to the composition of situation aspect. The unspecified NPs can have the value of either $[+$ count $]$ or [ - count]. For the moment, let us set aside external arguments and examine internal arguments alone. Rule 3 shows that verbs are the sole determinant of situation types when internal arguments are optionally absent (e.g. (I2a, b)). Rules 4 and 5 show that with [-telic] verbs, NP-arguments do not affect situation types (e.g. (I2c, d)) while with [+telic] verbs (including compound verbs derived at the nucleus level), the telicity values of situations at the core level are determined by the nominal feature of internal arguments (e.g. (I2e, f)).

(I2) (a) the flames go out (in/*for one hour)

$$
\mathrm{NP}_{[+ \text {count }]}+\mathrm{Verb}_{[+ \text {telic }]} \Rightarrow \text { Core }_{[+ \text {telic }]}
$$

(b) a buzz of excitement went around (for/*in hours)

$\mathrm{NP}_{[+ \text {count }]}+$ Verb $_{[- \text {telic }]} \Rightarrow$ Core $_{[- \text {telic }]}$

(c) he buzzed the skyscraper hotel (for/*in 5 minutes)

$\mathrm{NP}_{[+ \text {count }]}+\mathrm{Verb}_{[- \text {telic }]}+\mathrm{NP}_{[+ \text {count }]} \Rightarrow$ Core $_{[- \text {telic }]}$

(d) which (=documentary) pours cold water on the daredevil exploits of the stars (for/*in three days)

$\mathrm{NP}_{[+ \text {count }]}+\mathrm{Verb}_{[- \text {telic }]}+\mathrm{NP}_{[- \text {count }]} \Rightarrow$ Core $_{[- \text {telic }]}$

(e) (they) stapled on 80 shoulder-length dreadlocks (in/*for seven hours).

$\mathrm{NP}_{[+ \text {count }]}+\operatorname{Verb}_{[+ \text {telic }]}+\mathrm{NP}_{[+ \text {count }]} \Rightarrow$ Core $_{[+ \text {telic }]}$

(f) I opened supermarkets (for $/ *$ in 5 years)

$$
\mathrm{NP}_{[+ \text {count }]}+\mathrm{Verb}_{[+ \text {telic }]}+\mathrm{NP}_{[- \text {count }]} \Rightarrow \text { Core }_{[- \text {telic }]}
$$

We tested these rules using the Weekly and FLOB corpora. However, as the corpora are only annotated with part-of-speech information, but not with

[II] More precisely, only accomplishment verbs are relevant because achievement verbs encode a result, which is not affected by arguments. 
Sentence patterns and examples

$$
[+ \text { telic }] \quad[- \text { telic }]
$$

I. $\mathrm{NP}_{[+ \text {count }]}+$ Verb $_{[+ \text {telic }]}$

e.g. all this happened

\begin{tabular}{|c|c|}
\hline $2 \mathrm{I}$ & 0 \\
\hline $100 \%$ & $0 \%$ \\
\hline 0 & 20 \\
\hline $0 \%$ & $100 \%$ \\
\hline 3 & 0 \\
\hline $100 \%$ & $0 \%$ \\
\hline 0 & 2 \\
\hline $0 \%$ & $100 \%$ \\
\hline 43 & 0 \\
\hline $100 \%$ & $0 \%$ \\
\hline 4 & 0 \\
\hline $100 \%$ & $0 \%$ \\
\hline 0 & 6 \\
\hline $0 \%$ & $100 \%$ \\
\hline 3 & 27 \\
\hline $10 \%$ & $90 \%$ \\
\hline 0 & 3 \\
\hline $0 \%$ & $100 \%$ \\
\hline
\end{tabular}

2. $\mathrm{NP}_{[+ \text {count }]}+$ Verb $_{[- \text {telic }]}$

e.g. We joked

3. $\mathrm{NP}_{[- \text {count }]}+$ Verb $_{[+ \text {telic }]}$

e.g. anything goes wrong

4. $\mathrm{NP}_{[- \text {count }]}+\mathrm{Verb}_{[- \text {telic }]}$

e.g. nothing burns

5. $\mathrm{NP}_{[+ \text {count }]}+$ Verb $_{[+ \text {telic }]}+\mathrm{NP}_{[+ \text {count }]}$

e.g. I heard the plane

6. $\mathrm{NP}_{[- \text {count }]}+$ Verb $_{[+ \text {telic }]}+\mathrm{NP}_{[+ \text {count }]}$

e.g. language proved a barrier

7. $\mathrm{NP}_{[+ \text {count }]}+$ Verb $_{[+ \text {telic }]}+\mathrm{NP}_{[- \text {count }]}$

e.g. I opened supermarkets

8. $\mathrm{NP}_{[+ \text {count }]}+\mathrm{Verb}_{[- \text {telic }]}+\mathrm{NP}_{[+ \text {count }]}$

e.g. the plonker waggled his wings

9. $\mathrm{NP}_{[- \text {count }]}+\mathrm{Verb}_{[- \text {telic }]}+\mathrm{NP}_{[+ \text {count }]}$

e.g. Could anyone doubt his complete innocence

in this plot?

I0. $\mathrm{NP}_{[+ \text {count }]}+\mathrm{Verb}_{[- \text {telic }]}+\mathrm{NP}_{[- \text {count }]}$

e.g. which pours cold water on the daredevil exploits

0

3

of the stars

$0 \%$

$100 \%$

Total

74

6I

\section{Table 5}

Situation types in the FLOB sample

such semantic features as telicity and nominal values, a large-scale test proved impractical. Therefore, a segment of around 2,000 tokens was taken from FLOB (FLOB AI9) and further processed by hand to allow us to undertake this analysis. As the first step in processing, all clauses without verbs (e.g. Just like that), with stative verbs (e.g. We're no fools) and with reporting verbs (e.g. said Keith) were excluded from the sample, ${ }^{12}$ then all of the remaining clauses were annotated with semantic features such as telicity values for verbs and nominal values for NPs. If a complex sentence consisted of two clauses, it was counted as two simple clauses (e.g. (I2d)).

After processing, a testbed of I35 semantically annotated simple clauses was obtained. As can be seen from the results in Table 5, the situation types

[I2] Stative verbs are supposed to be irrelevant to a final spatial endpoint (cf. Verkuyl I989: 79; Tenny I994: I3). 
denoted by clauses with the pattern of NP + Verb are solely determined by verbs; 24 situations with [ + telic] verbs (rows I and 3 ) are all telic whereas 22 situations with [-telic] verbs (rows 2 and 4) are all atelic, irrespective of the nominal features of their external arguments. In clauses with the pattern of NP + Verb + NP, situation types are the composite result of verbs and their internal arguments. With [-telic] verbs, atelic situations result irrespective of the nominal feature of internal arguments. 33 out of 36 clauses (9I.7\%) with [-telic] verbs (rows 8-IO) denote atelic situations, the remaining three $(8.3 \%)$ denote telic situations simply because they take a $\mathrm{PP}_{\text {[goal] }}$, which provides a final spatial endpoint (see the discussion of Rule 6 below). With [+ telic] verbs, internal arguments also play a role. All 47 clauses with [+ count] object NPs (rows 5-6) denote telic situations whereas the six clauses with [-count] object NPs (row 7) are atelic.

It is interesting to note that the nominal features of internal indirect arguments may also affect situation types (cf. Moens 1987: 15I); for example:

(I3) (a) Henry went through torture (for/*in 7 hours) to conjure up some giggles.

(b) Henry went through the revolving door (in/*for 2 minutes).

The in/for-PP tests show that (13a) is an atelic situation while (13b) is telic. The aspectual characterizations differ because the NP in the first instance is [-count] whereas that in the second is [+ count].

We must now return to the question of external arguments. Our data clearly show that external arguments do not contribute to situation aspect because 'external arguments cannot measure out the event' (Tenny I994: 62). But for this view to be tenable, one should be able to account for the following atypical, yet valid, examples $:^{13}$

(I4) (a) Brandy evaporated from these barrels for 50 years.

(b) A gallon of brandy evaporated from these barrels in 50 years.

The apparently confusing contrast between (I4a) and (I4b) is caused by different interpretations of the for-PP. English uses this device to express DURATION (I5a, b); SCOPE (I5c, d); and INTENTION (I5e). In French, duration is expressed by pour 'for' whereas scope is expressed by pendant 'during' (cf. also Moens \& Steedman I988: 2I). In Chinese, expressions like yi-nian 'one year' are used to indicate duration (e.g. chicheng yitan sanshiduo-nian '(She) played an outstanding role in art circles for more than 30 years') or intention (pan-le san-nian xing ' $(\mathrm{He})$ was jailed for 3 years'). Scope is expressed by the preposition (zai) ... zhong 'during', or (yi)lai 'from ... on' if the situation lasts till the beginning of the stretch of speech in which it is discussed. Tenny (I994: 6) notes that the relevant interpretation of for an hour, when used as a test for telicity values, is that the event continues for an

[13] We would like to thank Jim Miller for these examples. 
hour's duration but does not necessarily stop after one hour. This means that only the duration meaning of a for-PP as used in (15a) is relevant. The for-PP in ( $15 \mathrm{~b}$ ) is irrelevant because for a few minutes refers to the duration of the resultant state of an achievement, namely, his absence from the room. In (I4a), for 50 years indicates a scope meaning rather than a duration meaning and hence is clearly not related to the test for telicity.

(I5) (a) I cried for days [...].

(b) He left the room for a few minutes.

(c) No doubt: Burgundy was having its hottest summer for years.

(d) For years he was considered a 'promising actor' [...].

(e) He was jailed for $\mathbf{I} 8$ months [...].

Even if the nominal features of subject NPs do affect situation types, (I4a) should be compatible with an in-PP because the subject NP, though a mass noun, is [+ count] and evaporate is an achievement verb. Consider the following example:

(I6) Opinion poll leads can evaporate overnight.

In this sentence, the subject NP is a bare plural. Nevertheless, the adverbial overnight can be replaced with in an hour quite felicitously.

Mass nouns or bare plurals may not necessarily be [-count]. Sometimes they can have a definite referent (i.e. an existential reading) rather than an indefinite referent (i.e. a generic reading; cf. Carlson 1977; Dowty 1979: 83f.). Consider the following examples from Dowty (ibid.):

(I7) (a) Tyrants ruled Wallachia for 250 years.

(b) Elephants are quite easily trained.

In (I7a), some particular tyrants, not tyrants in general, are clearly referred to, even though the NP is a bare plural. This is in contrast with the bare plural elephants in ( $\mathrm{I} 7 \mathrm{~b})$, which has to be taken as referring to elephants in general rather than a particular group of elephants (cf. Dowty 1979: 84). By the same token, the mass noun brandy in (I4a) necessarily has an existential reading. It has specific reference, namely, the brandy that evaporated from those barrels and thus is $[+$ count $] .^{14}$

[I4] A $J L$ referee pointed out to us that brandy in (I4a) did not have specific reference and, therefore, was not [+ count], because the French version is du cognac and not le cognac. We agree that in French, the partitive $d u$ but not the definite article le is appropriate in this context because the brandy that evaporated from the barrels represents only some of the brandy in the world. Obviously, it is not likely that ALL of the brandy in the world evaporated from those barrels between, say, 1900 and 1950. The use of the partitive $d u$ justifies our interpretation that brandy in (I4a) has specific reference, as $d u$ is a short form of de le rather than de un. According to the referee, 'The speaker asserts that some brandy evaporated; having introducing some brandy, the speaker can refer to the brandy that evaporated'. We agree with the referee, but our analysis remains the same-brandy in this context has specific reference and is thus [+ count]. 
We briefly discussed Verkuyl's (1989) assertion concerning external arguments in section 2. Verkuyl (1993: 23) further claims, with reference to the contrast between sentences like those in (I8), that 'the subject-NP plays a decisive role in aspect construal'. Dowty (1979: 63) also argues that 'if an indefinite plural occurs even as the subject of an achievement, the sentence is acceptable with durative adverbials' (e.g. (I9a)).

(I8) (a) For months patients here died of jaundice. (Verkuyl I993: 23)

(b) *These two patients died of jaundice for months. (ibid.)

(19) (a) Tourists discovered the quaint little village for years. (Dowty I979: 63)

(b) *John discovered the quaint little village for years. (ibid.)

(20) (a) jiucheng ganran bingdu zhe shu-tian nei ji $90 \%$ infect virus person a-few-day within right-after gao buzhi end-up no-cure

'Ninety per cent of those infected with the Ebola virus die in a few days.'

(b) huanzhe ji-ri zhinei jiu hui da chuxue er wang patient a-few-day within right-after likely big bleed then die 'Patients (of the disease) die of bleeding in a few days.'

(c) Nikki Lauda won the Monaco Grand Prix for several years.

(Moens \& Steedman I988: 2I)

The for-PPs in (I8a) and (I9a) clearly carry a scope meaning because it is plausible to say For months [patients died of jaundice IN A FEW DAYS] and [Tourists discovered the quaint little village IN A FEW HOURS] for years. Situations with [-count] external arguments can indeed take an in-PP, as shown in (20a, b). (I8b) and (I9b) are unacceptable simply because the situations described are not repeatable. Once someone dies, they are dead. Similarly, a person cannot discover the same thing twice. Repeatable achievements, in contrast, can take a for-PP felicitously, as shown in (20c), because for-PPs may coerce an aspectual shift at the clause level (see section 6.3). The resulting situation is a derived ITERATIVE ACHIEVEMENT (see section 7 below).

To test Rules $3-5$ in Chinese, a segment of 5,826 characters (File 9557IOI) was selected from the Weekly Corpus for further processing, following the same procedure as used on the FLOB sample. The result is given in Table 6 . In the table, rows $\mathrm{I}-3$ show that when internal arguments are optionally absent, verbs alone determine situation types, irrespective of the nominal features of external arguments. Rows 4-5 show that with [+telic] verbs (or more precisely, accomplishment verbs), situation types depend upon the nominal features of internal arguments. Rows $6-7$ show that [ - telic] verbs always result in atelic situations, irrespective of the nominal features of NParguments. This is different from the pattern in English because Chinese does

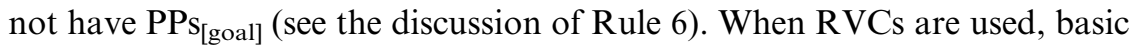




\begin{tabular}{|c|c|c|}
\hline Sentence patterns & {$[+$ telic $]$} & [-telic] \\
\hline I. NP $[+$ count $]+\operatorname{Verb}_{[+ \text {telic }]}$ & $\begin{array}{c}7 \\
\mathrm{I} 00 \%\end{array}$ & $\begin{array}{l}0 \\
0 \%\end{array}$ \\
\hline 2. $\mathrm{NP}_{[+ \text {count }]}+\operatorname{Verb}_{[- \text {telic }]}$ & $\begin{array}{l}0 \\
0 \%\end{array}$ & $\begin{array}{l}24 \\
100 \%\end{array}$ \\
\hline 3. $\mathrm{NP}_{[- \text {count }]}+\operatorname{Verb}_{[- \text {telic }]}$ & $\begin{array}{l}0 \\
0 \%\end{array}$ & $\begin{array}{c}\mathrm{I} \\
\mathrm{IOO} \%\end{array}$ \\
\hline 4. $\mathrm{NP}_{[+ \text {count }]}+\mathrm{Verb}_{[+ \text {telic }]}+\mathrm{NP}_{[+ \text {count }]}$ & $\begin{array}{l}72 \\
\mathrm{I} 00 \%\end{array}$ & $0 \%$ \\
\hline 5. $\mathrm{NP}_{[+ \text {count }]}+\operatorname{Verb}_{[+ \text {telic }]}+\mathrm{NP}_{[- \text {count }]}$ & $\begin{array}{l}0 \\
0 \%\end{array}$ & $\mathrm{I}$ \\
\hline 6. $\mathrm{NP}_{[+ \text {count }]}+\mathrm{Verb}_{[- \text {telic }]}+\mathrm{NP}_{[+ \text {count }]}$ & $\begin{array}{l}0 \\
0 \%\end{array}$ & $\begin{array}{c}6 \\
\mathrm{IOO} \%\end{array}$ \\
\hline 7. $\mathrm{NP}_{[+ \text {count }]}+\operatorname{Verb}_{[- \text {telic }]}+\mathrm{NP}_{[- \text {count }]}$ & $\begin{array}{l}0 \\
0 \%\end{array}$ & 2 \\
\hline 8. $\operatorname{Verb}_{[+ \text {telic }]}+\mathrm{NP}_{[+ \text {count }]}$ & $\begin{array}{l}3 \\
100 \%\end{array}$ & $\begin{array}{l}0 \\
0 \%\end{array}$ \\
\hline Total & 82 & 34 \\
\hline
\end{tabular}

Table 6

Situation types in the Weekly corpus sample

verbs are turned into derived achievements at the nucleus level (cf. section 6.I above). The absence of an external argument in the pattern in row 8 provides further evidence for our argument that subject NPs do not affect situation types.

Here are some examples:

(2I)
(a) ta laihui
zou-le (yi-ge xiaoshi)
he back-and-forth walk-LE one-CL hour
'He walked back and forth (for an hour).'
$\mathrm{NP}_{[+ \text {count }]}+\mathrm{Verb}_{[- \text {telic }]} \Rightarrow$ Core $_{[- \text {telic }]}$
(b) zuifan (wu-fenzhong nei) taopao-le
criminal five-minute within escape-LE
'The criminal escaped (in 5 minutes).'
$\mathrm{NP}_{[+ \text {count }]}+\mathrm{Verb}_{[+ \text {telic }]} \Rightarrow$ Core $_{[+ \text {telic }]}$
(c) zuo'anfenzi (zai shi-fenzhong nei) xiaochu-le jiaoyin
criminal in ten-minute within remove-LE footprint
'The criminal removed his footprints (in Io minutes).'
$\mathrm{NP}_{[+ \text {count }]}+\mathrm{Verb}_{[+ \text {telic }]}+\mathrm{NP}_{[+ \text {count }]} \Rightarrow$ Core $_{[+ \text {telic }]}$

As noted above, a situation with a [-telic] verb in English is normally atelic, but the situation changes if there is a prepositional phrase specifying a final spatial endpoint. A PP-argument used in the spatial dimension can be 
a $\mathrm{PP}_{[\text {Goal }]}$, as in (22a), a $\mathrm{PP}_{[\text {Locative }]}$, as in (22b), or a $\mathrm{PP}_{\text {[Directional] }}$, as in (22c) (cf. Smith 1997). Only $\operatorname{PPs}_{[\text {Goal] }}$ change the telicity value of situations with [ - telic] verbs from minus to plus. PPs ${ }_{[\text {Locative] }}$ and PPs ${ }_{\text {[Directional] }}$ do not have such an effect. The role of $\mathrm{PPs}_{[\text {Goal] }}$ can be expressed as

Rule 6: NP $+\operatorname{Verb}_{[- \text {telic }]}+\mathrm{PP}_{[\text {Goal }]} \Rightarrow$ Core $_{[+ \text {telic }]}$

Compare the following examples.

(22) (a) He got up and walked to the door (*for/in Io minutes).

(b) Then we walked side by side along the wall (for/*in Io minutes).

(c) She walked briskly towards Upper Street (for/*in Io minutes).

The in/for-adverbial tests show that $(22 a)$ is telic while $(22 b, c)$ are atelic. These sentences all have the same [-telic] verb walk, and the only difference lies in the features of their PP-arguments. Evidently, it is the $\mathrm{PP}_{\text {[goal] }}$ that has contributed to the $\left[+\right.$ telic] value of (22a). A commonly recognized $\mathrm{PP}_{\text {[goal] }}$ is to-PP (cf. Vendler I967, Smith I997). To test the reliability of Rule 6, the co-occurrence of motion verbs with to-PPs in FLOB was examined. ${ }^{15}$ There are 134 such instances in the corpus, and it was found that each of them can take an in-PP felicitously at the core level, whether the verb is [+telic] (as in (23a)) or [-telic] (as in (23b)) at the nucleus level. This provides evidence that Rule 6 is valid in English. Interestingly, some directional adverbials have an effect similar to that of $\mathrm{PPs}_{\text {[goal] }}$ in that they also change the telicity value of a situation, as shown in (24) below.

(23) (a) She disappeared to the kitchen.

(b) He strolled to the door.

(24) She walked home/downstairs (in/*for five minutes). (Brinton I988: 5I)

In Chinese, however, there are only $\mathrm{PP}_{\mathrm{S}_{\text {[Locative] }}}(\mathrm{e} . \mathrm{g} .(25 \mathrm{a}))$ and $\mathrm{PPS}_{\text {[Directional] }}$ (e.g. (25b)), since goals are normally indicated by RVCs (e.g. (25c)). Thus, Rule 6 does not apply to Chinese. Consider the following examples:

(25) (a) *Yang Bingming (yi-ge xiaoshi nei) zai jizhen shang Yang Bingming one-CL hour within on market-town on guang-le

stroll-LE

'*Yang Bingming strolled in the market town (in an hour).'

(b) *(yi-ge xiaoshi nei) gan-wang-LE huochezhan

one-CL hour within rush-towards-le railway-station

'*(They) rushed towards the railway station (in an hour).'

[I5] Only motion verbs are relevant because only these verbs co-occurring with to-PPs can be taken strictly in the spatial dimension. To make the data manageable, only motion verbs in the past tense are counted. 
(c) liang ren (yi-ge xiaoshi nei) gan-dao-le shi duo two persons one-CL hour within rush-arrive-LE ten more gongli yuan de yi-ge jizhen shang

kilometer far GEN one-CL market-town on

'The two of them walked to the market town more than Io km away (in an hour).'

It is expected that the $\mathrm{PP}_{\text {[Locative] }}$ zai jizhen shang 'in the market town' and the $\mathrm{PP}_{\text {[Directional] wang huochezhan 'towards the railway station' do not }}$ change the telicity value of (25a) and (25b); therefore, these two situations are incompatible with in-PPs. (25c) is a telic situation, but the change in its telicity value is attributable to the RVC dao 'to reach', that is, gan-dao is a derived achievement verb (cf. section 6.I).

\subsection{Clause level composition}

The telicity and boundedness values of core-level situations may also be changed by non-arguments such as peripheral adjuncts and viewpoint aspect at the clause level. The roles of contributing elements can be expressed as follows:

Rule 7: Core $\left[-\right.$ bounded] + for $-\mathrm{PP} /$ from $\ldots$ to $\Rightarrow$ Clause $_{[+ \text {bounded] }}$

Rule 8: Core $_{[+ \text {telic }]}+$ for $-\mathrm{PP} /$ from ... to $\Rightarrow$ Clause $_{[- \text {telic }]}$

Rule 9: Core $_{[ \pm \text {bounded] }}+$ temporal quantifier $\Rightarrow$ Clause $_{[+ \text {bounded] }}$

Rule Io: Core $_{[+ \text {telic }]}+$ progressive $\Rightarrow$ Clause $_{[- \text {telic }]}$

Rules 7 and 8 show that temporal adverbials like for-PPs and from ... to play the dual roles of (i) specifying a temporal endpoint for a [-bounded] situation and (ii) stripping a telic situation of its final spatial endpoint if the endpoint falls beyond the specified time frame.

\begin{tabular}{|c|c|c|c|c|c|c|c|c|}
\hline & & ILS & SLS & $\mathrm{ACT}$ & SEM & $\mathrm{ACC}$ & $\mathrm{ACH}$ & Total \\
\hline \multirow[t]{4}{*}{ for-PP } & FLOB & 38 & I9 & 99 & I & 8 & 37 & 202 \\
\hline & & I $8.8 \%$ & $9.4 \%$ & $49 \%$ & $0.5 \%$ & $4 \%$ & $18.3 \%$ & $100 \%$ \\
\hline & Weekly & 3 & 2 & $6 I$ & 4 & 5 & I7 & 92 \\
\hline & & $3.3 \%$ & $2.2 \%$ & $66.3 \%$ & $4.3 \%$ & $5.4 \%$ & I $8.5 \%$ & $100 \%$ \\
\hline \multirow{4}{*}{$\begin{array}{l}\text { from... } \\
\text { to }\end{array}$} & FLOB & 7 & 3 & IO & 0 & 0 & 0 & 20 \\
\hline & & $35 \%$ & $15 \%$ & $50 \%$ & & & & $100 \%$ \\
\hline & Weekly & 0 & I & 3 & 0 & 0 & 2 & 6 \\
\hline & & & I $6.7 \%$ & $50 \%$ & & & $33.3 \%$ & $100 \%$ \\
\hline
\end{tabular}

Table 7

Distribution of for-PPs/from ... to in the corpora

These two rules were tested against the two corpora used in this paper. The distribution of for-PPs/from ... to is given in Table 7. As Rule 7 shows, 
for-PPs/from ... to function to provide a specific time frame. Therefore all core-level basic situation types with the feature values of [-bounded] and [ - telic] -73 states (including ILSs and SLSs), I73 activities and five semelfactives - are turned into temporally bounded situation types at the clause level. The following examples illustrate Rules 7 and 8:

(26) (a) He was chairman from '8I to '85.

(b) They were silent for a while.

(c) lian-le zhengzheng yi-nian, Yang Bingming kuai practise-LE whole one-year Yang Bingming nearly chushi le finish-apprenticeship PRT

'Having practiced for a whole year, Yang Bingming was soon to finish his apprenticeship.'

(d) da-le ni ji-tian?

beat-LE you how-many-day

'For how many days did they beat you?'

(27) They wrote from eight-thirty in the morning till twelve, and again from four till six.

(28) I stood and read the menu for a while, discovering it served mainly hamburgers.

In (26a, b), for example, He was chairman and They were silent are an openended ILS and SLS, respectively, but from '8I to '85 and for a while bound them temporally and turn them into a BOUNDED ILS and a BOUNDED SLS, respectively. Similarly in $(26 \mathrm{c}, \mathrm{d})$, the activity lian 'practice' and the semelfactive $d a$ 'beat' are temporally unbounded, but when for-PPs are used, they have a temporal boundary and become a BOUNDED ACTIVITY and a BOUNDED SEMELFACTIVE, respectively. On the other hand, as Rule 8 shows, when an accomplishment takes a for-PP/from ... to, its final spatial endpoint is stripped if the endpoint goes beyond the specified time frame. In (27), for example, the discourse suggests that the writing event is an accomplishment, but the from ... to expressions bound the telic situation before its final spatial endpoint is achieved. In other words, the writing event is not accomplished within the specified time frame and is thus turned into a bounded activity at the clause level. However, Rule 8 only applies to sOME accomplishments. For repeatable accomplishments whose endpoint falls within the specified time frame, for-PPs/from ... to do not remove their final spatial endpoint but rather give them an iterative reading. In our corpora, there are thirteen accomplishments taking for-PPs/from ... to, but Rule 8 only applies to six instances (two in English and four in Chinese). The others are still telic situations with iterative readings at the clause level. For example, in (28), the conjoined second clause suggests that the menu-reading event was accomplished, though it is not clear whether it was repeated within the specified time frame. 


\begin{tabular}{lllllc}
\hline Corpus & ACT & SEM & ACC & ACH & Total \\
\hline FLOB & 25 & 8 & 22 & 26 & $8 \mathrm{I}$ \\
& $30.9 \%$ & $9.9 \%$ & $27 . \mathrm{I} \%$ & $32 . \mathrm{I} \%$ & $\mathrm{I} \% 0 \%$ \\
Weekly & 23 & $\mathrm{I} \%$ & $\mathrm{I} 5$ & 7 & 55 \\
& $4 \mathrm{I} .8 \%$ & $\mathrm{I} 8.2 \%$ & $27.3 \%$ & $\mathrm{I} 2.7 \%$ & $\mathrm{I00} \%$ \\
\hline
\end{tabular}

Table 8

Distribution of temporal quantifiers in the corpora

The hypothesis that a for-PP may function to trigger a situation type shift from accomplishment to activity at the clause level explains the felicitous co-occurrence of some core-level accomplishments with both in-PPs and for-PPs, as observed by Dowty (I979: 6I):

(29) (a) He read a book for/in an hour.

(b) She combed her hair for/in five minutes.

Rule 9 shows that temporal quantifiers (e.g. once, twice and six times) have the same delimiting effect as for-PPs/from ... to. The frequencies of temporal quantifiers found in the corpora are given in Table $8 .{ }^{16}$ For accomplishments and achievements, their [ \pm bounded] value will not change when they are repeated for a specified number of times. For example, (30a) and (3Ia) have a temporal boundary as definite as, though not the same as, (30b) and (3Ib). Therefore, the 70 situations of these two types are irrelevant to Rule 9 and thus can be excluded from the analysis. On examination, it is found that all of the remaining situations, namely, 48 activities and eighteen semelfactives, have a temporal boundary at the clause level. As semelfactives shift between single event and multiple event readings (cf. section 5.I), they can be either [+ bounded] or [-bounded]. The event of 'stabbing', for example, can occur just once or repeatedly. But when it is delimited by the quantifier six times, as in (32a), it has a definite temporal boundary as expected. The activity 'xunshi' (meaning 'to look around'), as in (32b), is intrinsically [-bounded]. But when it is delimited by the quantifier yi-fan 'once', a temporal boundary is attached to it and the activity becomes temporally bounded. The effect of temporal quantifiers is more obvious in Chinese because the aspect marker -le is sensitive to a final endpoint, either temporal or spatial (cf. section 6.I). This contrasts strikingly with the simple (perfective) aspect in English. For example, if the quantifier six times in (32a) is removed, the English sentence is still felicitous; but if $y i$-fan 'once' in the Chinese example in $(32 \mathrm{~b})$ is removed, (32b) becomes unacceptable.

[I6] Only temporal quantifiers indicating a definite number of iterations were counted, therefore expressions like more than once, twice a week and several (many) times were excluded. 
Situation types

\begin{tabular}{lllllll} 
& SLS & ACT & SEM & ACC & ACH & Total \\
\hline Frequency & 2 & 73 & 2 & 7 & 4 & 88 \\
& $2.3 \%$ & $83 \%$ & $2.3 \%$ & $7.9 \%$ & $4.5 \%$ & $100 \%$ \\
\hline
\end{tabular}

Table 9

Distribution of the progressive in the Weekly Corpus

(30) (a) She read it once.

(b) She read it three times.

(3I) (a) Rovers lost the ball twice.

(b) Rovers lost the ball 5 times.

(32) (a) I stabbed her about six times.

(b) na hanzi zuoyou xunshi-le yi-fan, disheng shuo [...] that man left-right look-around-le one-CL, low-voice say 'That man looked around, and said in a low voice [...].'

Rule Io shows that viewpoint aspect also participates in the composition of situation aspect at the clause level. There are 88 instances of the progressive zai in the Weekly Corpus, which serve as the basis for the test. The progressive zai only occurs with dynamic situations (cf. section 4.I), as can be seen in Table 9.

As the progressive only changes the telicity value from plus to minus, atelic situations are irrelevant. Of the 88 situations taking the progressive $z a i$ in the Chinese corpus, eleven are [+telic] at the core level. But when they are presented with the progressive aspect, the final spatial endpoints of these situations are all excluded. Therefore, the progressive functions to trigger a situation type shift and coerce a telic situation into a derived activity at the clause level. Consider the following examples:

(33) (a) Meiguo zhengfu zheng zai zhengli yi-fen [...] dui the-US government right-now ZAI arrange one-CL against $\mathrm{Ri}$ maoyi zhicai qingdan. Japan trade sanction list

'The US Administration is preparing a list for trade sanctions against Japan.'

(b) You are writing a crime thriller and want to bump off a victim with a spectacular poisoning.

At the core level, the situations of 'the US Administration preparing a list' and 'you writing a crime thriller' are accomplishments with a final spatial endpoint. In (33b), for example, when the novel is completed, the writing event is accomplished. But when these situations are referred to by progressive expressions, they become atelic because their final spatial 
endpoints are excluded and no longer available at the clause level. In fact, as Comrie (1976:47) suggests, 'it is possible to state explicitly that the terminal point was never reached, as in Mary was singing a song when she died'.

Chinese is rich in delimiting devices. As well as those discussed above, the $d e$ resultative structure and the $b a / b e i$ constructions also function to delimit situations (cf. Yang 1995: 78), which can be expressed as:

Rule II : Core $_{[- \text {result }]}+d e$-construction $\Rightarrow$ Clause $_{[+ \text {result }]}$

Rule I2: Core $[-$ result $]+b a / b e i$-construction $\Rightarrow$ Clause $_{[+ \text {result }]}$

The structure of Verb $+d e+$ Complement can denote either resultativeness (e.g. da de toupoxueliu 'beat till one bleeds') or manner (e.g. chang de buhao 'not sing well'). Only resultative $d e$-constructions are relevant here. A total of 4I such instances were found in the Weekly Corpus, of which nine are SLSs (e.g. xia de bu gan kensheng 'be too scared to speak'), 22 are activities (e.g. $k u$ de siquhuolai 'to cry oneself half dead, to cry one's heart out'), nine are semelfactives (e.g. da de wo bu neng dong '(They) beat me so badly that I could not move') and one is an accomplishment (e.g. ba yi-guo shui shao de guntang ' $(\mathrm{He})$ boiled a pot of water to the boiling point'). All of the verb classes involved in resultative $d e$-constructions have the features [ + dynamic] and [-result]. This is as expected. ILS verbs cannot occur in this structure because de denotes the result state caused by an action, which is necessarily dynamic; achievement verbs cannot occur with de because they already encode a result themselves. At the clause level, all of the 4I [-result] verbs occurring in resultative $d e$-structures produce situations with a result attached to them (e.g. (34a)), thus they can take in-PPs felicitously and cannot be contradicted, as in (34b).

(34) (a) (wu-fenzhong nei) dou de Xiao Mao zhongyu kaihuaidaxiao five-minute within amuse DE Xiao Mao at-last laugh-heartily '(She) amused Xiao Mao so much that he burst into laughter at last (within 5 minutes).'

(b) dou de Xiao Mao zhongyu kaihuaidaxiao (*keshi amuse DE Xiao Mao at-last laugh-heartily but mei dou-cheng)

not amuse-succeed

'(She) amused Xiao Mao so much that he burst into laughter at last (*but she didn't succeed).'

In Chinese, $b a$ is an object modifier that preposes a direct object to the pre-verbal position (e.g. ban-le shouxu vs. ba shouxu ban-le 'went through formalities'), and bei represents the passive construction (e.g. bei yifa chengban 'be punished according to law'). Sentences with ba/bei structures always denote delimited situations with the implication of successful achievement of a result. In this sense, they have a function similar to that of RVCs. There are II 6 instances of $b a$ structures and 255 instances of $b e i$ structures in the Weekly Corpus, which are distributed as shown in Table Io. 


\begin{tabular}{llllllll}
\hline ba/bei & $\begin{array}{c}\text { ACT } \\
(-\mathrm{de})\end{array}$ & $\begin{array}{c}\text { ACT } \\
(+\mathrm{de})\end{array}$ & $\begin{array}{c}\text { SEM } \\
(-\mathrm{de})\end{array}$ & $\begin{array}{c}\text { SEM } \\
(+\mathrm{de})\end{array}$ & ACC & ACH & Total \\
\hline ba & 5 & 6 & 2 & 2 & $\mathrm{IO}$ & $9 \mathrm{I}$ & $\mathrm{II} 6$ \\
& $4.3 \%$ & $5 . \mathrm{I} \%$ & $\mathrm{I} .7 \%$ & $\mathrm{I} .7 \%$ & $8.6 \%$ & $78.4 \%$ & $\mathrm{IOO} \%$ \\
bei & 44 & 3 & 2 & 4 & $\mathrm{I} 5$ & $\mathrm{I} 87$ & 255 \\
& $\mathrm{I} 7.2 \%$ & $\mathrm{I} .2 \%$ & $0.8 \%$ & $\mathrm{I} .6 \%$ & $5.9 \%$ & $73.3 \%$ & $\mathrm{IOO} \%$ \\
\hline
\end{tabular}

Table Io

$\mathrm{Ba} /$ bei constructions in the Weekly Corpus

As achievements and situations taking the resultative $d e$-structure already encode a result, 99 instances of $b a$ and 194 instances of bei can be excluded from the analysis. As situations encoding a result cannot be contradicted by a conjoined clause (cf. section 4.4), the contradiction test was used to discover resultatives. The test shows that none of the remaining seventeen situations with $b a$ and 6r situations with bei can be contradicted. Consider the examples in (35) and (36) below:

(35) (a) ye ba ta yuesu-le ji-ge zhongtou also BA him detain-LE a-few-CL hour

(*keshi mei yuesu-cheng)

but not detain-succeed

'(We) also kept him in custody for several hours (*but didn't succeed).'

(b) Jiang Xiaoming ba ta da-le dun (*keshi mei da-dao) Jiang Xiaoming BA him beat-LE CL but not beat-succeed 'Jiang Xiaoming gave him a beating (*but didn't succeed).'

(c) ba zhe-ge yisi gaosu-le Zhang (*keshi mei gaosu-wan)

BA this-CL meaning tell-LE Zhang but not tell-finish '(Yang) told Zhang about it (*but didn't finish it).'

(36) (a) ta zuowei renzhi bei Jiang Xiaoming yi-huo kouya

he as hostage BEI Jiang Xiaoming one-group detain

(*keshi mei kouya-cheng)

but not detain-succeed

'He was detained as a hostage by Jiang Xiaoming and others (*but this was not successful).'

(b) jiantou turan bei ren qin-qin dian-le yi-xia shoulder suddenly BEI person gently touch-LE one-CL

(*keshi mei dian-dao) but not touch-succeed

'Suddenly (his) shoulder was touched gently (*but the touch missed him).' 
(c) Gorn yisheng bei sha hou (*meiyou si)

Gorn doctor BEI kill after not die

'After Dr. Gorn was killed (*he didn't die),'

At the core level, yuesu 'to keep in custody' in (35a) and kouya 'to detain' in (36a) refer to activities, da 'to beat' in (35b) and dian 'to touch' in (36b) refer to semelfactives, while gaosu 'to tell' in (35c) and sha 'to kill' in (36c) refer to accomplishments. ${ }^{17}$ None of these expressions encodes a result. But when the $b a$ and bei structures are used, they all encode a result and can no longer be contradicted.

The discussion in this section has shown that lexical-level verb classes determine a range of possible situation types that clauses may have, for the clauses in which they occur. The specific situation type of a clause comes as a result of the interaction between verb classes and complements (nucleuslevel), arguments (core-level) and non-arguments such as peripheral adjuncts and viewpoint aspect (clause-level).

\section{Sentential LeVel: Situation types}

Chinese and English have the same six basic types of situations at the sentential level: activities, semelfactives, accomplishments, achievements, ILSs and SLSs. Basic situation types share the same feature values with verb classes of the same name (see section 5). Except for accomplishments, all of the others have various derived situation types which vary from their basic types with respect to their durativity or boundedness value. ${ }^{18}$ The salient features of these situation types are summarized in Table II.

The situation types discussed here are the final result of composition at the clause level. When basic states and activities are temporally bounded by delimiting mechanisms, bounded states and bounded activities are the result. Derived activities can also be obtained from basic accomplishments delimited by for/from ... to-PPs or the progressive. Accomplishments do not have a derived situation type. Basic semelfactives have a single-event reading; when they occur with temporal quantifiers or durative temporal adverbials, or when they take the progressive or durative aspect, they become derived ITERATIVE SEMELFACTIVES. When achievement verbs take plural [+ count] NPs or temporal quantifiers, derived iterative ACHIEvements result. Following are examples of these situation types:

- Basic ILS

ta ai Mali 'He loved Mary.'

[17] Kill in English is an achievement verb. Its Chinese equivalent is the RVC form sha-si 'to kill-dead'. In Chinese sha 'to kill' alone is an accomplishment verb.

[18] Because the derived situation type of accomplishment has exactly the same feature values as its basic type (cf. (30a) and (30b)), these two are not differentiated. 


\begin{tabular}{llccccc}
\hline Situation type & {$[ \pm$ dyn $]$} & {$[ \pm$ dur $]$} & {$[ \pm$ bnd $]$} & {$[ \pm$ telic $]$} & {$[ \pm$ result $]$} \\
\hline ILS & basic & - & + & - & - & - \\
& derived & - & + & + & - & - \\
SLS & basic & \pm & + & - & - & - \\
& derived & \pm & + & + & - & - \\
ACC & & + & + & + & + & - \\
ACT & basic & + & + & - & - & - \\
& derived & + & + & $\pm{ }^{\mathrm{a}}$ & - & - \\
SEM & basic & + & - & \pm & - & - \\
& derived & + & + & \pm & - & - \\
ACH & basic & + & - & + & + & + \\
& derived & + & + & + & + & + \\
\hline
\end{tabular}

$[a]$ Derived activities have the value of [ \pm bounded] because they represent a complicated category. When basic activities are delimited by a specific time frame, they are [ + bounded]; when accomplishment verbs take [-count] NPs or the progressive, the derived activities are [-bounded].

\section{Table II}

Feature matrix system of situation types

- Derived ILS (basic ILS $\Rightarrow$ derived ILS) ta ai Mali ai-le san-nian 'He loved Mary for three years.'

- Basic SLS Yuehan hen shengqi 'John was angry.'

- Derived SLS (basic SLS $\Rightarrow$ derived SLS) Yuehan sheng-le yi-ge xiaoshi de qi 'John was angry for an hour.'

- Basic activities: ta tui-le yi-liang che 'He pushed a cart.'

- Derived activities ta tui che tui-le yi-ge xiaoshi 'He pushed the cart for an hour.'

ta xie lunwen xie-le yi-ge xiaoshi/ta zai xie lunwen

'He wrote his thesis for an hour/was writing his thesis.'

- Basic semelfactives dengta shan-le yi-xia 'The beacon flashed once.'

- Derived semelfactives (basic SEM $\Rightarrow$ derived SEM) ta kesou ke-le 5 fenzhong/san-ci/zai kesou 'He coughed for 5 minutes/three times/was coughing.'

- Accomplishments ta xie-le yi-feng xin 'He wrote a letter.'

- Basic Achievements ta ba chabei da-po-le 'He broke the cup.' 
- Derived achievements (basic $\mathrm{ACH} \Rightarrow$ derived $\mathrm{ACH}$ )

ta zhuyi-dao-le wenzhang zhong de san-chu cuowu

'He noticed three errors in the paper.'

\section{CONCLUSION}

The corpus-based two-level model developed in this paper provides a more refined aspectual classification and gives a more systematic account of the compositional nature of situation aspect than previous models. Mourelatos' (I98I: 199) criticism of Vendler and Kenny also applies to all of the models reviewed so far in this paper, though it should be noted that Mourelatos himself does not provide an explanation of the 'determinants' of situation aspect. Vendler (I967) is confined to the lexical level whereas Verkuyl (I993) works only at the core level. While Smith (1997) and Shirai (I99I) utilize a classification system similar to ours, they do not differentiate between the lexical and sentential levels of situation aspect. In fact, with their classification systems (note the difference between Shirai's definition of RESULT and ours), it is quite impossible to treat verb classes and situation types separately. However, the distinction between their one-level approach and our two-level approach is more than cosmetic as a two-level approach can model situation aspect in a more structured way and provide a clearer account of the composition of situation aspect. The dichotomous treatment of states in our model also gives a unified explanation of the felicitous cooccurrence of some states with the progressive, which is absent in previous proposals. Last but not least, our model, which is based on and verified by corpus data, represents an innovative attempt to marry a corpus-based approach and a theory-driven approach to aspect.

Situation aspect is basically a semantic concept. The basis for natural language semantics is 'the conceptual system that emerges from everyday human experience' (Sweetser I990: I). As such, one must refer to 'viewing', 'conceiving' and 'conceptualising' in speaking of aspect (cf. Matthews I990: Iof.). ${ }^{19}$ Consequently, verb classes, situation types and the distinguishing features of situation aspect show great similarities cross-linguistically (cf. also Zhang 1995: 4I; Peterson 1997). As such, Smith (1997: 17) is able to talk about situation types 'at an abstract level that holds across languages'. As can be seen from sections 4-7, situation aspect in Chinese and English shows

[19] The way of talking about aspect in terms of 'conceiving' and 'viewing', as introduced by Comrie (1976: 3, 4I), has recently been criticized for the metaphorical use of these terms (e.g. Klein, Li \& Hendriks 2000: 730). Klein et al. argue that since situations - unlike houses and little dogs - are abstract entities and cannot be SEEN at all, the term 'viewing' is at best used metaphorically. This argument, however, is not tenable because, as Matthews (I990: Iof.) points out, viewing 'means not merely seeing' as Klein et al. suggest, 'but a mode of thinking'. Conceiving and viewing are useful terms when talking about an abstract, cognitive-semantic concept like aspect. 
great similarity at both the lexical and the sentential levels. This is in spite of the fact that our model does indicate some cross-linguistic differences between English and Chinese. For example, the entailment test for telicity works well in English but not in Chinese (see section 4.3); Rule 6, governing $\mathrm{PPs}_{\text {[goal] }}$, only applies in English (see section 6.2). These differences, nevertheless, are not inherent in situation aspect. Rather, they are related to grammatical categories. Therefore, while the six verb classes and eleven situation types manifest, and are determined by, the same five distinguishing features, linguistic tests for these features may vary across languages because different languages vary in linguistic forms. Viewpoint aspect, on the other hand, varies significantly across languages because it is primarily a grammatical category. Bybee, Perkins \& Pagliuca (1994:300), for example, observe that grammatical categories like perfectives demonstrate 'many language specific differences'. As a by-product of developing the two-level model of situation aspect on the basis of corpus data from two typologically unrelated languages, this paper also claims that the difference between situation aspect and viewpoint aspect lies in the fact that the former is language-independent and the latter is language-dependent. Thus, our two-level model of situation aspect has also contributed to the understanding of natural language.

\section{REFERENCES}

Bach, E. (198I). On time, tense, and aspect: an essay in English metaphysics. In Cole, P. (ed.), Radical pragmatics. New York: Academic Press. 62-8I.

Bach, E. (1986). The algebra of events. Linguistics and Philosophy 9. 5-16.

Bauer, G. (1970). The English 'perfect' reconsidered. Journal of Linguistics 6. I89-198.

Bennet, M. \& Partee, B. (1978). Toward the logic of tense and aspect. Indiana University Linguistics Club.

Brinton, L. (1988). The development of English aspectual systems. Cambridge: Cambridge University Press.

Bybee, J., Perkins, R. \& Pagliuca, W. (1994). The evolution of grammar: tense, aspect, and modality in the languages of the world. Chicago: University of Chicago Press.

Carlson, G. (1977). Bare plurals and the English kind. Linguistics \& Philosophy I. 413-457.

Carlson, L. (I98I). Aspect and quantification. In Tedeschi \& Zaenen (eds.), 3I-64.

Chief, L., Hung, C., Chen, K., Tsai, M. \& Chang, L. (2000). What can near synonyms tell us? Computational Linguistics and Chinese Language Process 5. 47-60.

Chierchia, G. (1995). Individual-level predicates as inherent generics. Carlson, G. \& Pelletier, F. (eds.), The generic book. Chicago: University of Chicago Press. 176-223.

Comrie, B. (1976). Aspect. Cambridge: Cambridge University Press.

Dowty, D. (1979). Word meaning and montague grammar. Dordrecht: Reidel.

Francis, G., Hunston, S. \& Manning, E. (1996). Collin Cobulld grammar patterns I: verbs. London: HarperCollins.

Garey, H. (I957). Verbal aspect in French. Language 33. 9I-IIO.

Hundt, M., Sand, A. \& Siemund, R. (1998). Manual of information to accompany the FreiburgLOB Corpus of British English ('FLOB'). [Available at http://www.hit.uib.no/icame/flob/ index.htm]

Hunston, S. (2002). Corpora in applied linguistics (Cambridge Applied Linguistics). London: Cambridge University Press.

Jakobson, R. (I97I). Selected writings II. The Hague: Mouton.

Jespersen, O. (1924). The philosophy of grammar. London: George Allen and Unwin.

Kenny, A. (1963). Action, emotion and will. London: Routledge \& Kegan Paul. 
Klein, W., Li, P. \& Hendriks, H. (2000). Aspect and assertion in Mandarin Chinese. Natural Language \& Linguistic Theory 18. 723-770.

Kučera, H. (1982). Markedness and frequency: a computational analysis. In Horecky, J. (ed.), COLING 82. Academia. I67-I73.

Leech, G. (197I). Meaning and the English verb. London: Longman.

Lindvall, A. (1997). Aspect marking and situation types in Greek, Polish and Swedish (Working Paper 46). Linguistics Department, Lund University. I97-2I6.

Link, C. (1983). The logical analysis of plurals and mass terms, a lattice-theoretic approach. In Schwarze, C. \& von Stechow, A. (eds.), Meaning, use, and interpretation of language. Berlin: Springer. $302-323$.

Lyons, J. (1977). Semantics (2 vols.). Cambridge: Cambridge University Press.

Lys, F. \& Mommer, K. (I986). The problem of aspectual verb classification: a two-level approach. In Farley, A., Farley, P. \& McCullough, K. (eds.), Papers from the 22nd Regional Meeting, Chicago Linguistic Society (CLS 22, Part I). Chicago Linguistic Society. 216-230.

Matthews, S. (1990). A cognitive approach to the typology of verb aspect. Ph.D. dissertation, University of Southern California.

McEnery, A. \& Wilson, A. (200I). Corpus linguistics (2nd edn.). Edinburgh: Edinburgh University Press.

Meyer, C. (2002). English corpus linguistics: an introduction. Cambridge: Cambridge University Press.

Moens, M. (1987). Tense, aspect and temporal reference. Ph.D. dissertation, Edinburgh University.

Moens, M. \& Steedman, M. (I988). Temporal ontology and temporal reference. Computational Linguistics I4. I5-28.

Mourelatos, A. (I98I). Events, processes, and states. In Tedeschi \& Zaenen (eds.), I9I-2I2.

Olsen, M. (1994). The semantics and pragmatics of lexical aspect features. Studies in the Linguistic Sciences 24. 36I-375.

Peterson, P. (1997). Fact, proposition, event. Dordrecht: Kluwer.

Salaberry, R. \& Shirai, Y. (eds.) (2002). The L2 acquisition of tense-aspect morphology. Amsterdam: John Benjamins.

Seuren, P. (1998). Western linguistics: a historical introduction. Oxford: Blackwell.

Shirai, Y. (I99I). Primacy of aspect in language acquisition: simplified input and prototype. $\mathrm{Ph} . \mathrm{D}$. dissertation, University of California.

Shirai, Y. (2002). The prototype hypothesis of tense-aspect acquisition in second language. In Salaberry \& Shirai (eds.), 455-478.

Shirai, Y. \& Andersen, R. (I995). The acquisition of tense-aspect morphology: a prototype account. Language 7I. 743-762.

Siewierska, A. (199I). Functional grammar. London: Routledge.

Smith, C. (1983). A theory of aspectual choice. Language 59. 479-50I.

Smith, C. (I988). Event types in Mandarin. In Chan, M. \& Ernst, T. (eds.), Proceedings of the 3rd Ohio State University Conference on Chinese Linguistics. Bloomington, IN: Indiana University Linguistics Club. 215-243.

Smith, C. (I99I). The parameter of aspect. (Ist edn.). Dordrecht: Kluwer.

Smith, C. (1997). The parameter of aspect. Dordrecht: Kluwer. [Ist edn. I99I.]

Sweetser, E. (1990). From etymology to pragmatics (Cambridge Studies in Linguistics 54). Cambridge: Cambridge University Press.

Tedeschi, P. \& Zaenen, A. (eds.) (I98I). Tense and aspect (Syntax and Semantics I4). New York: Academic Press.

Tenny, C. (1994). Aspectual roles and the syntax-semantics interface. Dordrecht: Kluwer.

Van Valin, R. (forthcoming). The syntax-semantics-pragmatics interface: an introduction to role and reference grammar. Cambridge: Cambridge University Press.

Van Voorst, J. (1988). Event structure. Amsterdam: John Benjamins.

Vendler, Z. (1967). Linguistics in philosophy. New York: Cornell University Press.

Verkuyl, H. (1989). Aspectual classes and aspectual composition. Linguistics \& Philosophy I2. 39-94.

Verkuyl, H. (1993). A theory of aspectuality (Cambridge Studies in Linguistics 64). Cambridge: Cambridge University Press. 


\section{SITUATION ASPECT}

Xiao, Z. (2002). A corpus-based study of aspect in Mandarin Chinese. Ph.D. thesis, Lancaster University.

Xiao, Z. \& McEnery, A. (forthcoming). Aspect in Chinese. Amsterdam: John Benjamins.

Yang, S. (1995). The aspectual system of Chinese. Ph.D. dissertation, University of Victoria.

Zhang, L. (1995). A contrastive study of aspectuality in German, English and Chinese (Berkeley Insights in Linguistics and Semiotics 19). New York: Peter Lang.

Authors' address : Department of Linguistics and Modern English Language,

Lancaster University, Lancaster LAI $4 Y T$, U.K.

E-mail:z.xiao@lancaster.ac.uk, a.mcenery@lancaster.ac.uk 